\title{
A gp41 MPER-specific Llama VHH Requires a Hydrophobic CDR3 for Neutralization but not for Antigen Recognition
}

\author{
David Lutje Hulsik ${ }^{19}$, Ying-ying Liu ${ }^{29 a}$, Nika M. Strokappe ${ }^{2}$, Simone Battella ${ }^{2}$, Mohamed El Khattabi ${ }^{2}$, \\ Laura E. McCoy ${ }^{3}$, Charles Sabin ${ }^{1}$, Andreas Hinz ${ }^{1 \text { ab }}$, Miriam Hock ${ }^{1}$, Pauline Macheboeuf ${ }^{1}$, \\ Alexandre M. J. J. Bonvin ${ }^{4}$, Johannes P. M. Langedijk ${ }^{5{ }^{\circ c}}$, David Davis ${ }^{6}$, Anna Forsman Quigley ${ }^{3}$, \\ Marlén M. I. Aasa-Chapman ${ }^{3}$, Michael S. Seaman 7 , Alejandra Ramos ${ }^{8}$, Pascal Poignard ${ }^{8,9}$, \\ Adrien Favier ${ }^{10,11,12}$, Jean-Pierre Simorre ${ }^{10,11,12}$, Robin A. Weiss ${ }^{3}$, C. Theo Verrips ${ }^{2,13}$, \\ Winfried Weissenhorn ${ }^{1 *}$, Lucy Rutten ${ }^{2 *}$
}

1 Unit of Virus Host Cell Interactions (UVHCI), UMI 3265, Université Joseph Fourier-EMBL-CNRS, Grenoble, France, 2 Biomolecular Imaging (BMI), Faculty of Science, Utrecht University, Utrecht, The Netherlands, 3 MRC/UCL Centre for Medical Molecular Virology, Division of Infection and Immunity, University College London, London, United Kingdom, 4 Bijvoet Center for Biomolecular Research, Faculty of Science, Utrecht University, Utrecht, The Netherlands, 5 Pepscan Therapeutics BV, Lelystad, The Netherlands, 6 Department of Virology, Biomedical Primate Research Centre (BPRC), Rijswijk, The Netherlands, 7 Division of Viral Pathogenesis, Beth Israel Deaconess Medical Center, Harvard Medical School, Boston, Massachusetts, United States of America, 8 Department of Immunology and Microbial Science, International AIDS Vaccine Initiative Neutralizing Antibody Center, The Scripps Research Institute, La Jolla, California, United States of America, 9 International AIDS Vaccine Initiative, New York, New York, United States of America, 10 CNRS, Institut de Biologie Structurale-Jean-Pierre Ebel, Grenoble Cedex, France, 11 CEA, Institut de Biologie Structurale-Jean-Pierre Ebel, Grenoble Cedex, France, 12 UJF-Grenoble-1, Institut de Biologie Structurale-Jean-Pierre Ebel, Grenoble Cedex, France, 13 QVQ BV, Utrecht, The Netherlands

\begin{abstract}
The membrane proximal external region (MPER) of the HIV-1 glycoprotein gp41 is targeted by the broadly neutralizing antibodies 2F5 and 4E10. To date, no immunization regimen in animals or humans has produced HIV-1 neutralizing MPERspecific antibodies. We immunized Ilamas with gp41-MPER proteoliposomes and selected a MPER-specific single chain antibody $(\mathrm{VHH}), 2 \mathrm{H} 10$, whose epitope overlaps with that of mAb $2 \mathrm{~F} 5$. Bi-2 $\mathrm{H} 10$, a bivalent form of $2 \mathrm{H} 10$, which displayed an approximately 20 -fold increased affinity compared to the monovalent $2 \mathrm{H} 10$, neutralized various sensitive and resistant HIV1 strains, as well as SHIV strains in TZM-bl cells. X-ray and NMR analyses combined with mutagenesis and modeling revealed that $2 \mathrm{H} 10$ recognizes its gp41 epitope in a helical conformation. Notably, tryptophan 100 at the tip of the long CDR3 is not required for gp41 interaction but essential for neutralization. Thus bi-2H10 is an anti-MPER antibody generated by immunization that requires hydrophobic CDR3 determinants in addition to epitope recognition for neutralization similar to the mode of neutralization employed by mAbs $2 \mathrm{~F} 5$ and $4 \mathrm{E} 10$.
\end{abstract}

Citation: Lutje Hulsik D, Liu Y-y, Strokappe NM, Battella S, El Khattabi M, et al. (2013) A gp41 MPER-specific Llama VHH Requires a Hydrophobic CDR3 for Neutralization but not for Antigen Recognition. PLoS Pathog 9(3): e1003202. doi:10.1371/journal.ppat.1003202

Editor: Ronald C. Desrosiers, Harvard University, United States of America

Received September 25, 2012; Accepted January 7, 2013; Published March 7, 2013

Copyright: ( 2013 Lutje Hulsik et al. This is an open-access article distributed under the terms of the Creative Commons Attribution License, which permits unrestricted use, distribution, and reproduction in any medium, provided the original author and source are credited.

Funding: This work was supported by the Bill \& Melinda Gates Foundation as part of the Collaboration for AIDS Vaccine Discovery (CAVD grant 38637) Combined Highly Active Anti- Retroviral Microbicides (CHAARM:http://chaarm.eu/), the Dutch Foundation for Scientific Research (NWO) through a VICI grant (no. 700.56.442) (AMJJB), the TGE RMN THC Fr3050 (JPS) and the LabEX GRAL (WW). MH is supported by a post-doctoral fellowship from Sidaction and WW is supported by the Institut Universitaire de France. The funders had no role in study design, data collection and analysis, decision to publish, or preparation of the manuscript.

Competing Interests: The authors have declared that no competing interests exist.

* E-mail: weissenhorn@embl.fr (WW); L.Rutten@uu.nl (LR)

wa Current address: Tianjin Medical University, Tianjing, China.

ab Current address: Institute of Biochemistry, Goethe-University Frankfurt, Frankfurt/Main, Germany.

ac Current address: Crucell Holland BV, Leiden, The Netherlands.

9 These authors contributed equally to this work.

\section{Introduction}

The trimeric HIV-1 envelope glycoprotein (Env), composed of its receptor binding subunit gp120 and the fusion protein gp41, is the main target for neutralizing antibodies. Although recent studies have demonstrated the potential of the human immune system to produce broadly neutralizing antibodies (bnAbs) directed against gp120 [1-10], generation of antibodies with broad crossclade neutralization activity via recombinant Env immunization has been rare [11-14]. This may be due in part to the long time frame required to generate such antibodies as well as to multiple evasive strategies developed by the virus [15-17].

Because Env gp4l contains highly conserved sequences that are exposed during the conformational changes leading to membrane fusion $[18,19]$ a considerable effort is underway to target gp41 with a focus on the membrane proximal external region (MPER). The MPER is recognized by the broadly neutralizing antibodies (bnAbs) 2F5, Z13, 4E10 and 10E8 [9,20-23]. They interact with 


\section{Author Summary}

Due to the absence of an effective vaccine or cure for acquired immunodeficiency syndrome (AIDS), HIV-1 infections still result in high mortality. Two antibodies, 2F5 and 4E10, previously isolated from HIV-1 infected patients, prevent infections by binding to the MPER of gp41, a part of the virus that is difficult to access and only transiently exposed. Here, we immunized llamas with a gp41-based immunogen and subsequently isolated a small antibody fragment $(\mathrm{VHH})$ that can easily access and recognize the MPER. We showed that a unit of two VHH, named bi-2H10, was indeed capable of preventing HIV-1 from infecting cells. We determined the three dimensional structure of the $\mathrm{VHH}$ and mapped its interaction site to an MPER region that overlaps with the $2 \mathrm{~F} 5$ epitope. The $2 \mathrm{H} 10 \mathrm{VHH}$ displays a membrane binding component important for neutralization that resembles that of $2 \mathrm{~F} 5$. In conclusion, we have developed an immunogen and a small antibody that may have great potential for development of novel anti-HIV/ AIDS vaccines and treatments.

linear epitopes of the MPER [9,24-26] and gp41-mAb interaction most likely prevents refolding of gp 41 into the six-helical bundle conformation [27-29]. Notably, 2F5 and 4E10 are among the broadest cross-reactive human neutralizing antibodies directed against HIV-1 gp41 while recently-described 10E8 combines this extensive breadth with substantially increased potency $[9,22]$. The potencies of $2 \mathrm{~F} 5$ and $4 \mathrm{E} 10$ are confirmed by their ability to prevent HIV-1 transmission in rhesus macaques by passive immunization [30-35].

Numerous studies have been performed with purified gp41 proteins and gp41-derived peptides in an attempt to induce such antibodies by immunization; however, with very limited success so far [36-45]. This was partly attributed to the fact that both $4 \mathrm{E} 10$ and under some experimental conditions also 2F5 display lipid binding and potential polyreactivity [46], which may be a special feature of anti-HIV antibodies [47]. However mAb 10E8 does not bind lipids and is not polyreactive [9]. 2F5 and 4E10 contain hydrophobic residues within the third complementarity-determining region of the heavy chain (CDR H3), which do not contact the antigen directly, but are required for virus neutralization [48-51]. CDR H3 was suggested to insert into the viral membrane and extract membrane-embedded MPER leading to tight binding [52,53]. In addition CDR H3 of 2F5 may function in destabilizing the helical region downstream of the core $2 \mathrm{~F} 5$ epitope leading to the extended-loop conformation of the 2F5 epitope [54]. Both models are consistent with the finding that neutralization activity of MPER antibodies depends on the transmembrane region allowing functional MPER exposure [55]. Furthermore, MPER antibody epitopes of most primary isolates become only accessible after receptor/co-receptor-binding induced conformational changes in Env [56,57]. In addition, MPER mAb Env recognition was reported to induce gp120 shedding leading to irreversible neutralization effects [58]. Moreover, MPER antibody epitope access may be size-restricted [59], which is consistent with the proposal that such antibodies target the transient fusion-intermediate conformational state of gp41 [60] that is also difficult to access by HR 1-specific neutralizing antibodies [61-63]. Accordingly, anti-MPER-like neutralization activity in patient sera was reported to be rare [64-67] or absent $[68,69]$. This was attributed to the fact that MPER-specific antibodies in acutely infected individuals are polyreactive [70] and their B cells may undergo clonal deletion [71]. However, a recent study suggested that
10E8-like potent anti-MPER antibodies occur frequently in sera with high neutralizing breadth and potency without exhibiting autoreactivity such as lipid interaction [9].

Thus a major challenge remains to induce MPER-specific neutralizing antibodies upon immunization. Therefore we immunized two llamas with proteoliposomes containing trimeric gp41 consisting of the HIV-1 Env transmembrane region and MPER. Llamas (Lama glama) and other Camelidae produce classical antibodies as well as heavy chain-only antibodies [72]. Notably, $\mathrm{VHH}$ (variable domain of the heavy chain of a heavy chain only antibody) specific for gp120 with broad neutralizing activity have been successfully produced by immunization before [73-78]. Here we report the functional and structural characterization of the llama anti-MPER VHH 2H10. Our data suggest that this is the first MPER-specific antibody induced by immunization that employs similar structural features as mAbs $2 \mathrm{~F} 5$ and $4 \mathrm{E} 10$ for neutralization. 2H10 requires a hydrophobic CDR3 for neutralization but not for interaction with its epitope, like mAbs $2 \mathrm{~F} 5$ and $4 \mathrm{E} 10$. Futhermore, $2 \mathrm{H} 10$ binds to a $2 \mathrm{~F} 5$ overlapping epitope that is in an alpha-helical conformation, which provides important insights for the development of MPER based vaccines.

\section{Materials and Methods}

\section{Ethics statement}

This study was carried out in strict accordance with the Dutch Experiments on Animals Act 1997. In accordance with article 18 of the Act the protocol was assessed and approved by the Animal Ethics Committee of the Utrecht University (Permit Number: DEC\#2007.III.01.013). All efforts were made to minimize discomfort related to immunizations and blood sampling. The animal welfare officers of the Utrecht University checked the mandatory administration and supervised the procedures and the well-being of the llamas that were used.

\section{Preparation of gp41 constructs}

The HIV-1 gp41 constructs 'gp4lCHRTM', clade B Cterminal Heptad Repeat (CHR), MPER and transmembrane (TM) regions (residues 629-706, HXB2c numbering), 'gp41GCN', gp41 residues 629-683 (HXB2c numbering) fused to a trimeric GCN4 leucine zipper [79], and 'gp41 INT', which has a similar design as reported [60] with the exception that the trimeric GCN4 zipper was fused in frame with part of gp4l NHR, were cloned into pETM-11 (EMBL, Heidelberg) or pETM-13 using standard PGR techniques. Proteins were expressed in Escherichia coli strains $\mathrm{C} 41$ or BL21. Cells were grown to an $\mathrm{OD}_{600}$ of 0.8 and induced with $1 \mathrm{mM}$ isopropyl-ß-D-thiogalactopyranoside (IPTG). Cells were harvested by centrifugation and lysed in either phosphate buffered saline (PBS) supplemented with 1\% 3-[(3cholamidopropyl)dimethylammonio]-1-propanesulfonate

(CHAPS) or lysed in $20 \mathrm{mM}$ tris(hydroxymethyl)aminomethane hydrogen chloride (Tris-HCl) $\mathrm{pH} 8.0,100 \mathrm{mM} \mathrm{NaCl}$, or in 20 mM Bicine pH 9.3, 100 mM NaCl, for 'gp41CHRTM', 'gp41GCN' and 'gp41 ${ }_{\text {INT }}$ ' respectively. Purification was performed using a $\mathrm{Ni}^{2+}$ affinity or Q-sepharose column ('gp41 $1_{\text {INT }}$ ') and gel filtration on a Superdex 200 column (GE Healthcare). Gp41 $1_{528-}$ 683 was produced as described [29].

\section{Preparation of immunogen}

The concentration of gp4lCHRTM was adjusted to $1 \mathrm{mg} / \mathrm{ml}$. Lipids POPC, POPE, POPS, Cardiolipin/Sphingomyelin and cholesterol (Avanti Polar Lipids) were dissolved in chloroform and mixed in a 1:2:1:2:5 ratio ( $w / w)$. After solvent evaporation, the lipid film was dried under vacuum. Multilamellar vesicles were 
obtained by resuspending the lipid film in PBS to a final concentration of $1 \mathrm{mg} / \mathrm{ml}$. After three quick freeze/thaw rounds the liposome suspension was extruded through a $100 \mathrm{~nm}$ membrane. Liposomes and gp41CHRTM were mixed in a 1:1 ratio (w/w). CHAPS was removed by extensive dialysis with PBS containing $0.1 \mathrm{mg} / \mathrm{ml}$ BioBeads (BioRad), changing the solution every eight hours for two days. The quality of gp4lCHRTM proteoliposomes was confirmed by dynamic light scattering (Malvern Nano ZS).

\section{Immunization and construction of phage libraries}

Two llamas (L6 and L7) were immunized intramuscularly with the gp41CHRTM reconstituted in the trimeric form into synthetic liposomes (gp41 proteoliposomes) without adjuvant. The immunization scheme consisted of a priming immunization at day 0 followed by 5 boosts, which were given at days 7, 14, 21, 28 and 35. During the prime and the first boost $0.25 \mathrm{mg}$ of gp41 and $0.5 \mathrm{mg}$ of lipids were used per injection. These amounts were halved for the remaining boosts. Importantly no adjuvants were used. The immune response was measured in the serum taken at day 21 and compared to day 0 . At day 43 lymphocytes were collected from the two llamas for construction of two separate phage libraries, as described previously [80]. The genes encoding for the $\mathrm{VHH}$ were amplified and cloned in the phage-display plasmid, pAX50. The plasmids were transferred to E. coli strain TG1 [supE hsd $\Delta 5$ thi $\Delta$ (lac-proAB) $\mathrm{F}^{\prime}(\operatorname{traD} 36$ proAB+,lacIq $\operatorname{lacZ} \Delta \mathrm{M} 15)]$.

\section{Selection of gp41-specific VHH}

Two rounds of selection with phage libraries were carried out by panning phages onto gp4l-proteoliposomes immobilized in microtiter plate wells. In the first round selection, gp41 proteoliposomes at 5, 1 and $0.2 \mu \mathrm{g}$ were coated in the wells of PolySorp (Nunc) microplate overnight at $4{ }^{\circ} \mathrm{C}$ followed by PBS containing 4\% Marvel dried skimmed milk (Premier International Foods UK Ltd) for one hour at room temperature. approximately $10^{10}$ of the phages, pre-incubated for 30 minutes in $2 \%$ skimmed milk in PBS and empty liposomes to reduce nonspecific binding, were then added to the wells for 2 hours followed by extensive washing (15 times) with PBS containing 0.05\% Tween 20 (PBS$\mathrm{T})\left(\right.$ the $5^{\text {th }}, 10^{\text {th }}$ and $15^{\text {th }}$ wash steps were done for $10 \mathrm{~min}$ ) and three times with PBS. The bound phages were eluted with $100 \mathrm{mM}$ TEA, neutralized with $1 \mathrm{M}$ Tris-HCl pH 7.5, and rescued by infection of the $E$. coli strain TG1, which were then plated on LB agar plates containing $100 \mu \mathrm{g} / \mathrm{ml}$ ampicillin and $2 \%$ glucose. The phages eluted from $1 \mu \mathrm{g}$ coated gp41 proteoliposomes in the first round yielded the highest enrichment of $\sim 100$ times. These were therefore chosen for further selection in a second round. The selected polyclonal phages were amplified in $E$. coli strain TG1 after infection with helper phages VCSM13 (Stratagene). After purification from the culture supernatant, phages were used as input for the second round selection. Lower concentrations of proteoliposomes $(0.5$ and $0.1 \mu \mathrm{g}$ per well) were coated. $\sim 10^{9}$ phages of the amplified phages were incubated in each well. After extensively washing away unbound phages, the bound phages were eluted by $100 \mu \mathrm{l}$ of $150 \mu \mathrm{g} / \mathrm{ml}$ human monoclonal antibodies of either $2 \mathrm{~F} 5$ or $4 \mathrm{E} 10$. TG1 cells were infected with the eluted phages. The infected TG1 cells were grown on LB agar plates containing $100 \mu \mathrm{g} / \mathrm{ml}$ ampicillin and $2 \%$ glucose to obtain individual colonies. The infected TG1 were also spotted on the LB agar plates supplemented with $100 \mu \mathrm{g} / \mathrm{ml}$ ampicillin and $2 \%$ glucose for the assessment of the efficiency of the selection. The enrichment of specific phages was estimated in comparison with the phages that were eluted by an irrelevant human monoclonal antibody (Remicade, Schering-Plough) or with the phages eluted from the empty wells. DNA inserts of a number of selected phages binding to gp41 were recloned to plasmid pAX51 using the restriction sites SfiI and BstEII.

\section{Phage ELISA}

MaxiSorp (Nunc) plate wells were coated overnight at $4{ }^{\circ} \mathrm{C}$, with gp41-GCN in PBS. After blocking of the wells with 4\% skimmed milk in PBS, they were incubated with VHH fused to M13 phages in the presence of $2 \%$ skimmed milk. The wells were washed with PBS-T, and bound phages were detected by incubation with a mouse monoclonal antibody against M13 phage coupled to horse radish peroxidase (HRP). The amount of HRP was visualized by the addition of O-phenylenediamine (OPD) supplemented with $0.03 \% \mathrm{H}_{2} \mathrm{O}_{2}$. The reactions were stopped by the addition of $1 \mathrm{M}$ $\mathrm{H}_{2} \mathrm{SO}_{4}$ and the optical density was measured at $490 \mathrm{~nm}$.

\section{Production and purification of gp41-specific $\mathrm{VHH}$}

TG1 strains expressing monoclonal $\mathrm{VHH}$ were cultivated in $2 \times$ YT medium supplemented with $100 \mu \mathrm{g} / \mathrm{ml}$ of ampicillin until the optical density of culture medium reached 0.5 at $600 \mathrm{~nm}$. Then $1 \mathrm{mM}$ IPTG was added to induce $\mathrm{VHH}$ production for 5 hours at $37^{\circ} \mathrm{C}$. VHH were extracted from the periplasmic fraction and bound to Talon metal-affinity resin (Clontech 635504). After washing away unbound material, the bound VHH were eluted by $300 \mathrm{mM}$ imidazole in PBS. The eluted VHH were dialyzed against PBS with two buffer changes. The $\mathrm{VHH}$ were dialyzed twice for 1.5 hours at room temperature, followed by dialysis overnight at $4^{\circ} \mathrm{C}$. The $\mathrm{VHH}$ were analyzed on $15 \%$ acrylamide sodium dodecyl sulfate polyacrylamide gel electrophoresis (SDS-PAGE) stained by Coomassie Brilliant Blue and a Western blot using the antibody against the myc-tag (9E10).

\section{Binding of $\mathrm{VHH}$ to HIV-1 envelope proteins in ELISA}

The binding of the VHH to HIV-1 envelope was performed on the immobilized gp41 and gp140-92UG037 in the microtiter plate (MaxiSorp from Nunc) in ELISA. $200 \mathrm{ng}$ Gp41-GCN or $280 \mathrm{ng}$ gp140-92UG037 protein were coated in the wells of microtiter plates overnight at $4^{\circ} \mathrm{C}$ followed by incubation with $4 \%$ skimmed milk to block non-specific binding. Dilution series of purified $\mathrm{VHH}$ were incubated with the coated wells for one hour at room temperature followed by the removal of unbound $\mathrm{VHH}$ by washing three times with PBS-T and one time with PBS. Bound VHH were detected with anti-myc tag antibody (9E10) and donkey anti mouse peroxidase (DAMPO). The antibodies were incubated for one hour and washed with PBS-T and PBS between each incubation. The plates were developed using OPD containing $0.03 \% \mathrm{H}_{2} \mathrm{O}_{2}$. The reaction was stopped with $1 \mathrm{M} \mathrm{H}_{2} \mathrm{SO}_{4}$. The optical density was measured at $490 \mathrm{~nm}$.

\section{Binding of $\mathrm{VHH}$ to membrane anchored Env}

Titrating amounts of antibodies were added to JR-FL HIV-1 Env-transfected 293T cells expressing either cleaved or uncleaved Env, incubated for $1 \mathrm{~h}$ at $37^{\circ} \mathrm{C}$ and washed with FACS buffer (PBS, 5\% heat-inactivated fetal calf serum [HIFBS], 0.02\% azide). MAbs b6, b12, and 4E10 were detected with a secondary anti-IgG Ab conjugated to phycoerythin (Jackson ImmunoResearch). MAb b12 and the VHH 2H10, bi-2H10 and bi-2H10 W100A were biotinylated and detected with streptavidin PE. MAb b6 binding is weak on cleaved Env, confirming that most Env is cleaved [81]. Binding was analyzed using flow cytometry, and binding curves were generated by plotting the mean fluorescence intensity of antigen binding as a function of antibody concentration. 


\section{Bivalent $\mathrm{VHH}$ construction}

PCR was used to amplify the VHH sequences. Different primer sets designed to amplify the $\mathrm{VHH}$ that will be located at the $\mathrm{N}$ terminus and the $\mathrm{VHH}$ that will be located at the $\mathrm{C}$ terminus of the bivalent VHH. The primers at the $3^{\prime}$ of the N-terminal VHH and at the $5^{\prime}$ of the C-terminal $\mathrm{VHH}$, may encode a flexible sequence glycine-serine (GS) linker represented by a repeat of the pentapeptide "G-G-G-G-S", also called 5GS. These same primers contain a unique restriction site $($ Bam $\mathrm{HI})$. We constructed bi-2H10 with 5GS, 15GS, and 25GS linkers and with the linker GGGGSGGGGSGGGGGGS, called 17GS. For the studies we used the bi-2H10 with the $17 \mathrm{GS}$ linker, unless specified differently. After PCR amplification, the generated fragments were cleaved at a unique N-terminal restriction site (Sfi restriction site) and Bam HI for the VHH that will be located at the $\mathrm{N}$ terminus, and with $B a m \mathrm{HI}$ and at a unique C-terminal restriction site (BstEII) for $\mathrm{VHH}$ that will be located at the $\mathrm{C}$ terminus. The fragments are ligated into pAX51, which was digested with SfiI and BstEII.

\section{Lipid binding assays}

Antibodies were mixed with liposomes having the lipid composition as described above in PBS and their buffer was adjusted to $40 \%$ sucrose. The $40 \%$ sucrose mixture was overlaid stepwise with $30,20,10$ and $5 \%$ sucrose and centrifuged in a Ti55 swinging bucket rotor for $18 \mathrm{~h}$ at $50 \mathrm{~K} \mathrm{rpm}$. Six fractions were recovered from the gradient and samples thereof were analyzed by SDS-PAGE.

For ELISA analysis, cardiolipin from bovine heart (SIGMA, C0563) and l- $\alpha$-phosphatidyl-l-serine from bovine brain (SIGMA, P7769) were dissolved in ethanol to a concentration of $5 \mathrm{mg} / \mathrm{ml}$ and further diluted with PBS to $50 \mu \mathrm{g} / \mathrm{ml}$ of which $100 \mu \mathrm{l}$ was coated per well in PolySorp plates (Nunc) overnight at room temperature without a cover foil to allow complete evaporation of the sample. As a control gp140-92UG037 was coated on a MaxiSorp plate (Nunc). Dilution series were prepared of $2 \mathrm{H10}$, bi2H10, 2F5 and 4E10. 2F5 and 4E10 were detected with the mouse anti-human IgG monoclonal 3E8 (SANTA GRUZ). The rest of the ELISA was performed as described above.

\section{Viruses}

HIV-1 IIIB was obtained from the Centralised Facility for AIDS Reagents (CFAR), NIBSC and propagated in H9 cells. Replicationcompetent NL43 stocks were prepared from a replication-competent HIV-1 molecular clone by transfection of 293T cells. All other used HIV-1 viruses were HIV-1 envelope pseudotyped viruses and

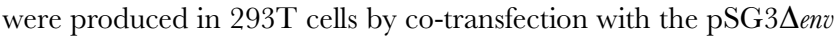
plasmid and the relevant envelope plasmid. The subtype B HIV-1 reference panel of envelope clones and the subtype $\mathrm{C}$ clones were obtained through the NIH AIDS Research and Reference Reagent Program, Division of AIDS, NIAID, NIH, USA. AC10.0 clone 29 and SC422661 clone 8 were contributed by David Montefiori, Feng Gao and Ming Li; ZM109F.PB4 was contributed by David Montefiori, Feng Gao, S Abdool Karim and G Ramjee; RHPA4259 clone 7 was contributed by B.H. Hahn and J.F. Salazar-Gonzalez. The SHIV clones were constructed at the BPRC by Zahra Fagrouch and Ernst Verschoor. The panel of transmitted subtype B (T/F) clones (WEAU-d15.410.787, 1006-11.C3.1601, 1054-07.TC4.1499, 1056-10.TA11.1826, 1012-11.TC21.3257) were provided by George Shaw and Beatrice Hahn.

\section{Cells}

TZM-bl cells were obtained through the NIH AIDS Research and Reference Reagent Program from J. C. Kappes, X. Wu, and
Tranzyme, Inc., and cultured in Dulbecco's modified Eagle medium (Invitrogen) containing 10\% (v/v) fetal calf serum (FCS).

\section{Neutralization assay}

Neutralization was measured using pseudovirus or $20050 \%$ tissue culture infective doses (TCID50) of virus in the TZM-bl cells as targets following the methods of Derdeyn et al. [82] Wei et al. [83] and $\mathrm{Li}$ et al. [84], with Bright-Glo luciferase reagent (Promega, Southampton, UK). The neutralization activity of each $\mathrm{VHH}$ was assayed in duplicate. No virus inactivation was observed with a negative control VHH. VHH IC50 titers were calculated using the XLFit4 software (ID Business Solutions, Guildford, UK). The HIV-1 neutralization potency of llama 6 \& 7 serum/plasma samples were also evaluated in TZM-bl. Neutralization was measured using 200 TCID50 of IIIB virus in the TZM-bl cellbased assay, as described above, using a Glomax plate reader (Promega). Serum samples were heat-inactivated to inactivate complement by incubation at $56^{\circ} \mathrm{C}$ for $1 \mathrm{~h}$ before use in neutralization assays. Threefold serial dilutions of llama sera were then tested, starting at a 1:5 dilution.

\section{Epitope mapping}

The binding of $\mathrm{VHH}$ and mAb to peptides was assessed in a Pepscan-based ELISA [85]. Structural aspects of antibody antigen interaction were revealed through small random peptide libraries [86]. Each VHH and mAb was titrated to ensure that optimal binding was achieved and that nonspecific binding was avoided. Each well in the card contained covalently linked peptides that were incubated overnight at $4{ }^{\circ} \mathrm{C}$ with $\mathrm{VHH}$ and $\mathrm{mAb}$, between 1 and $10 \mathrm{ng} / \mathrm{ml}$ in PBS containing 5\% horse serum (v/v), 5\% OVA $(\mathrm{w} / \mathrm{v})$, and $1 \%(\mathrm{v} / \mathrm{v})$ Tween 80 , or in an alternative blocking buffer of PBS containing 4\% horse serum $(\mathrm{v} / \mathrm{v})$, and $1 \%(\mathrm{v} / \mathrm{v})$ Tween 80. After washing, the plates were incubated with a HRP-linked rabbit anti-Ab (DakoCytomation) for $1 \mathrm{~h}$ at $25^{\circ} \mathrm{C}$. After further washing, peroxidase activity was assessed using substrate $(0.5 \mathrm{~g} / 1$ 2,2' -azinodi[3-ethyl-benzthiazolinesulfonate(6)] diammonium salt (ABTS)) with $0.006 \% \mathrm{H}_{2} \mathrm{O}_{2}$ in $0.18 \mathrm{M} \mathrm{Na}_{2} \mathrm{HPO}_{4}, 0.22 \mathrm{M}$ citric acid was added until the solution had a $\mathrm{pH}$ of 4 . The color development was quantified after 60 minutes using a charge-coupled device camera and an image-processing system.

\section{Protein expression and purification of $2 \mathrm{H} 10$ for crystallization}

The cDNA corresponding to $2 \mathrm{H} 10$ was synthesized (GeneArt) and cloned into vector pMEK220 (without 6his-tag or myc tag) and $2 \mathrm{H} 10$ was expressed in E. coli strain BL21gold (DE3) (Invitrogen). Cells were grown to an OD600 of 0.7 and induced with $1 \mathrm{mM}$ IPTG at $37^{\circ} \mathrm{C}$. After 5 hours cells were harvested by centrifugation and lysed by sonication in $0.02 \mathrm{M}$ 4-(2-hydroxyethyl)-1-piperazineethanesulfonic acid (HEPES), $0.1 \mathrm{M} \mathrm{NaCl}$, pH 7.4 (HEPES buffer). 2H10 was purified by affinity chromatography using a Protein A column (Roche). $2 \mathrm{H} 10$ was eluted with $0.01 \mathrm{M}$ glycine, $\mathrm{pH} 2.5$, and fractions containing $2 \mathrm{H} 10$ were neutralized with $1 \mathrm{M}$ Tris- $\mathrm{HCl}, \mathrm{pH}$ 8. These fractions were further purified by gel filtration on a Superdex 200 column (GE Healthcare) in HEPES buffer. Purity of the sample was confirmed on a $12 \%$ SDS-Tris-Tricine gel.

\section{Crystallization, data collection and structure determination}

$2 \mathrm{H} 10$ in complex with peptide 903 was subjected to crystallization at a concentration of $12 \mathrm{mg} / \mathrm{ml}$. Crystals were obtained by the vapor diffusion method in hanging drops, with equal volumes 
of antibody and reservoir solution (0.1 M Bicine, 3.2 $\mathrm{M} \mathrm{NH}_{4} \mathrm{SO}_{4}$, $\mathrm{pH}$ 9). The crystal was cryo-cooled at $100 \mathrm{~K}$ in reservoir buffer containing $25 \%(\mathrm{v} / \mathrm{v})$ glycerol. A complete dataset was collected at the ESRF (Grenoble, France) beamline ID14-4. Data were processed and scaled with MOSFLM [87], and SCALA [88]. The crystals belong to space group I23 with unit cell dimensions of $\mathrm{a}=89.95 \AA, \mathrm{b}=89.95 \AA, \mathrm{c}=89.95 \AA$ and $\alpha=90.00^{\circ}$. The structure was solved by molecular replacement using PHASER [89] and the VHH structure from Protein Data Bank (PDB) ID 3EZJ as a search model. An initial model was built with ARP/wARP [90] and completed by several cycles of manual model building with Coot [91] and refinement with refmac [92] using data to $1.3 \AA$ resolution. The final model contains $2 \mathrm{H} 10$ residues $1-122$. Molecular graphics figures were generated with PyMOL (W. Delano; http://www.pymol.org). Coordinates and structure factures have been deposited in the Protein Data Bank with accession ID $4 \mathrm{~B} 50$.

\section{NMR analyses of $2 \mathrm{H} 10$ and $2 \mathrm{H} 10$ in complex with its peptide epitope}

A ${ }^{13} \mathrm{C},{ }^{15} \mathrm{~N}$-labeled protein sample was prepared at a concentration of $0.95 \mathrm{mM}$ in $20 \mathrm{mM}$ HEPES buffer and $75 \mathrm{mM} \mathrm{NaCl}$ at $\mathrm{pH} 6.7$ with $10 \% \quad \mathrm{D}_{2} \mathrm{O}$. For the study of the peptide:2H10 complex, a solution of gp41 peptide ( ${ }_{655}$ KNEQELLELDKWASL $_{669}$.) was prepared at $7.9 \mathrm{mM}$ in the same HEPES buffer and $5 \mu \mathrm{l}$ were added step by step to the ${ }^{13} \mathrm{C},{ }^{15} \mathrm{~N}$-labeled protein sample. A final protein:peptide ratio of $1: 1.5$ was obtained and ${ }^{15} \mathrm{~N}$ HSQC experiments were recorded for each peptide addition in order to control the complete disappearance of the free form. Sequential backbone resonance assignments of free and peptide bound $2 \mathrm{H} 10$ were performed by recording series of $3 \mathrm{D}$ experiments using the BEST scheme (HNCO, HNCA, HNcoGACB, HNCACB) and the BEST-TROSY scheme (hNcocaNH, hNcocaNH) [93].

All NMR experiments were performed at $37^{\circ} \mathrm{C}$ on Agilent VNMRS 600 or $800 \mathrm{MHz}$ spectrometers equipped with tripleresonance $\left({ }^{1} \mathrm{H},{ }^{13} \mathrm{C}\right.$, and $\left.{ }^{15} \mathrm{~N}\right)$ coldprobes and shielded z-gradients. NMR data were processed with NMRPipe [94] and analyzed using the CcpNmr Analysis routines of CCPN [95]. Chemical shifts were referenced with respect to the $\mathrm{H}_{2} \mathrm{O}$ signal at $4.66 \mathrm{ppm}$ relative to DSS, using the ${ }^{1} \mathrm{H}: \mathrm{X}$ frequency ratios of the zero point according to Markley et al. [96].

\section{Surface plasmon resonance}

Surface plasmon resonance (SPR) analysis was performed with a Biacore T100 (GE Healthcare). As a flow buffer $10 \mathrm{mM}$ HEPES, $150 \mathrm{mM} \mathrm{NaCl}$, pH 7.4 with $0.005 \%$ Tween-20 was used. Gp14092UG037 was immobilized to 1500 response units using $50 \mu \mathrm{g} / \mathrm{ml}$ protein in flow buffer on an activated CM-5 sensor chip (GE Healthcare: BR-1000-50) according to the manufacturer's instructions. Specific binding to the target protein was corrected for nonspecific binding to the deactivated control channel. The flow rate was $30 \mu \mathrm{L} / \mathrm{min}$. Regeneration of the sensor chip was achieved with $4 \mathrm{M} \mathrm{MgCl}_{2}$ for 60 seconds at $50 \mu \mathrm{L} / \mathrm{min}$. Single concentration injections were all performed with $100 \mathrm{nM}$ of $\mathrm{VHH}$ for 60 seconds each. All data were measured in duplo and the curves superpose quite well. Data were analyzed with the Biacore T100 software version 2. Curves obtained for $2 \mathrm{H} 10$ could not be fitted well with the 1:1 Langmuir or heterogeneous ligand algorithms, but only with the two-state reaction algorithm. To establish whether $2 \mathrm{H} 10$ indeed binds with a two-state reaction, we injected $2 \mathrm{H} 10$ with different injection durations. This clearly showed that the dissociation rate is dependent on the injection time. The longer the duration of the injection, the stronger the interaction becomes and the dissociation rate decreases. We, therefore, fitted the curves belonging to the monovalent $2 \mathrm{H} 10$ $\mathrm{VHH}$ with the two-state reaction model. Curves of the bivalent $2 \mathrm{H} 10$ should be fitted with a combination of two-state reaction and bivalent analyte model, but due to a lack of availability of this model, the curves were fitted with the heterogeneous ligand fit and the two-state reaction fit.

Additional SPR analysis was performed using a Biacore 3000 (GE Healtcare). As a flow buffer $10 \mathrm{mM}$ HEPES, $150 \mathrm{mM} \mathrm{NaCl}$, pH 7.4, $50 \mu \mathrm{M}$ EDTA with $0.005 \%$ P-20 (GE Healthcare) was used. Gp41 INT or gp41 $1_{528-683}$ was immobilized to 1000 response units in a sodium acetate buffer, $\mathrm{pH} 4.5$, on an activated CM-5 sensor chip according to the manufacturer's instructions. Specific binding to the target protein was corrected for nonspecific binding to the deactivated control channel. The flow rate was $20 \mu \mathrm{l} / \mathrm{min}$. Regeneration of the sensor chip was achieved with $25 \mathrm{mM} \mathrm{NaOH}$ for 30 seconds at $50 \mu \mathrm{l} / \mathrm{min}$. Data were analyzed with the BIAevalution software version 4.1. The curves for $2 \mathrm{H} 10$ and $2 \mathrm{H} 10-\mathrm{W} 100 \mathrm{~A}$ on $\mathrm{gp} 41_{\mathrm{INT}}$ were fitted with separate association and dissociation, because global fittings, either 1:1 langmuir or two-state reaction, did result in reasonable $\mathrm{Chi}^{2}$ scores and residuals.

\section{Isothermal titration calorimetry}

Isothermal Titration Calorimetry (ITC) measurements were carried out at $25^{\circ} \mathrm{C}$ on a VP-ITC microcalorimeter (MicroCal). Both $2 \mathrm{H} 10$ and peptides were purified or dissolved, respectively, in a solution containing $20 \mathrm{mM}$ HEPES, pH 7.4 and $100 \mathrm{mM} \mathrm{NaCl}$. The samples were degassed for $20 \mathrm{~min}$ and centrifuged to remove any residuals prior to the measurements. The concentration of $2 \mathrm{H} 10$ in the sample cell was $10 \mu \mathrm{M}$ and that of peptide 903 or 904 in the syringe was approximately $100 \mu \mathrm{M}$. The peptides injected into buffer alone was used as a negative control. Data were fit to a single binding site model and analyzed using Origin version 5 (MicroCal) software.

\section{Site directed mutagenesis}

Site directed mutagenesis was performed by PCR with complementary oligos which carried the desired mutation, to amplify the whole plasmid. The oligo's were designed to be between 42-50 nucleotides long and have a melting temperature (salt adjusted, calculated on http://www.basic.northwestern.edu/ biotools/oligocalc.html) of approximately $80^{\circ} \mathrm{C}$. The PCR reaction was performed with $20 \mathrm{ng}$ of template DNA (2H10-wild type plasmid), $125 \mathrm{ng}$ each primers, $2 \mathrm{mM}$ DNTPs, Pfu buffer with $2 \mathrm{mM} \mathrm{MgSO}_{4}$ and 0.5 units of Pfu polymerase (Fermentas). The protocol consisted of an initial denaturation step at $95^{\circ} \mathrm{C}$ for $5 \mathrm{~min}$ followed by 16 cycles of $95^{\circ} \mathrm{C}$ for 30 seconds, $60^{\circ} \mathrm{C}$ for 1 minute and $68^{\circ} \mathrm{C}$ for 7 minutes, and a final step extension at $68^{\circ} \mathrm{C}$ for 10 min. DNA was cleaned with PGR Clean-up kit (MachereyNagel). Parental methylated DNA was digested with DpnI (Fermentas), followed by transformation into TG1 E. coli cells.

\section{Modeling of the gp41 peptide interaction with $2 \mathrm{H} 10$}

Models of gp4l peptide docked onto $2 \mathrm{H} 10$ were built with the webserver version "The HADDOGK web server for data-driven biomolecular docking" of HADDOCK2.1 [97] using CNS1.2 [98] for the structure calculations. The coordinates of $2 \mathrm{H} 10$ were taken from the crystal structure, and the gp 41 peptide coordinates were based on those of the helical peptide (653-QEKNEQELLELDKWASL-669) from the crystal structure of a late fusion intermediate of HIV-1 gp41 (PDB code: 2X7R [29]). Ambiguous interaction restraints were defined, based on the NMR chemical shift perturbation (CSP) mapping using the program SAMPLEX [99] 
and the epitope mapping. The SAMPLEX program takes as input a set of data and the corresponding three-dimensional structure and returns the confidence for each residue to be in a perturbed or unperturbed state. Residues 47-51, 57-62 and 95-99 identified as perturbed in $2 \mathrm{H} 10$ upon binding to gp 41 and residues 657,658 , 661, 662 and 665 identified from the epitope mapping, were used as interaction restraints for docking. Phi-psi angles were deduced from the ${ }^{13} \mathrm{G}$ chemical shifts using TALOS+ [100] and the resulting dihedral and $\mathrm{H}$-bond restraints were used in the modeling as well. The docking was performed with default HADDOCK parameters, except that random removal of restraints was turned off and the clustering cutoff was decreased to $2.5 \AA$ because of the small size of the peptide. Non-bonded interactions were calculated with the OPLS force field using a cutoff at $8.5 \AA$. The electrostatic potential $\left(\mathrm{E}_{\text {elec }}\right)$ was calculated by means of a shift function, while a switching function - between 6.5 and $8.5 \AA$ - was used for the Van der Waals potential $\left(\mathrm{E}_{\mathrm{vdw}}\right)$. The HADDOCK score is used to rank the generated models. It consists of a weighted sum of intermolecular electrostatics, Van der Waals, desolvation $\left(\Delta \mathrm{G}_{\text {solv }}\right)$ [101] and ambiguous interaction restraint (AIR) energies, defined as: Haddock Score $=0.2 E_{\text {elec }}$ $+1.0 E_{V d W}+1.0 E_{\Delta G s o l v}+0.1 E_{A I R}$

\section{Results}

\section{Immunization of llamas, library construction and selection of $\mathrm{VHH}$ against gp41}

Two llamas (L6 and L7) were immunized with the gp41 proteoliposomes composed of an HIV-1-like lipid envelope [102] and membrane-anchored gp4lCHRTM (Fig. 1). The presence of anti-gp41CHRTM proteoliposome antibodies in the plasma was confirmed by ELISA at day 21 post immunization. However, no significant neutralization was detected in the sera/plasma at day 21 and 43 compared to those of day 0 . Two phage display libraries were constructed and the selection of $\mathrm{VHH}$ targeting gp4l was performed in two rounds by direct panning of the phage display library on immobilized gp41 proteoliposomes. In the first round triethyl-amine (TEA) was used to elute the phages. In the second round a specific competitive elution with bnAbs $2 \mathrm{~F} 5$ or $4 \mathrm{E} 10$ was performed. Monoclonal VHH expressing TG1 clones from first and second round selections were screened for binding to detergent-solubilized gp41CHRTM and gp41-GCN (with pIIGCN in place of the transmembrane region) by phage ELISA. Approximately $80 \%$ of all monoclonal $\mathrm{VHH}$ displaying phages were positive for binding. In order to find $\mathrm{VHH}$ targeting specific binding sites, a competition ELISA between phages and bnAb 2F5 or $4 \mathrm{E} 10$ was performed. The phages with either strong binding signals, and/or binding signals that were inhibited by bnAb $2 \mathrm{~F} 5$ or $4 \mathrm{E} 10$ were chosen for further investigation with purified $\mathrm{VHH}$. Using ELISA, three of the VHH were found to bind to gp41GCN, gp41 proteoliposomes and gp140-92UG037. 2H10, which originated from llama 7 (L7), exhibited the highest maximum signal and was therefore chosen for the subsequent studies (see Fig. 2 for the sequence of $2 \mathrm{H} 10$ ). $2 \mathrm{H} 10$ competed for binding to gp41 with $2 \mathrm{~F} 5$, but not with $4 \mathrm{E} 10$.

\section{Epitope mapping of $2 \mathrm{H} 10$ with Pepscan analysis}

To determine the epitope of $2 \mathrm{H} 10$, its binding to a set of overlapping linear and cyclic peptides covering the gp41 MPER was measured. The best binding cyclic 15 -mer peptide covered the gp41 region from amino acid 655 to 669 (655 KNEQELLELDKWASL $_{669}$ ). This peptide was used as a seed for a library in which the amino acids on each position of the peptide was substituted by all other 19 natural amino acids. Probing this library with $2 \mathrm{H} 10$
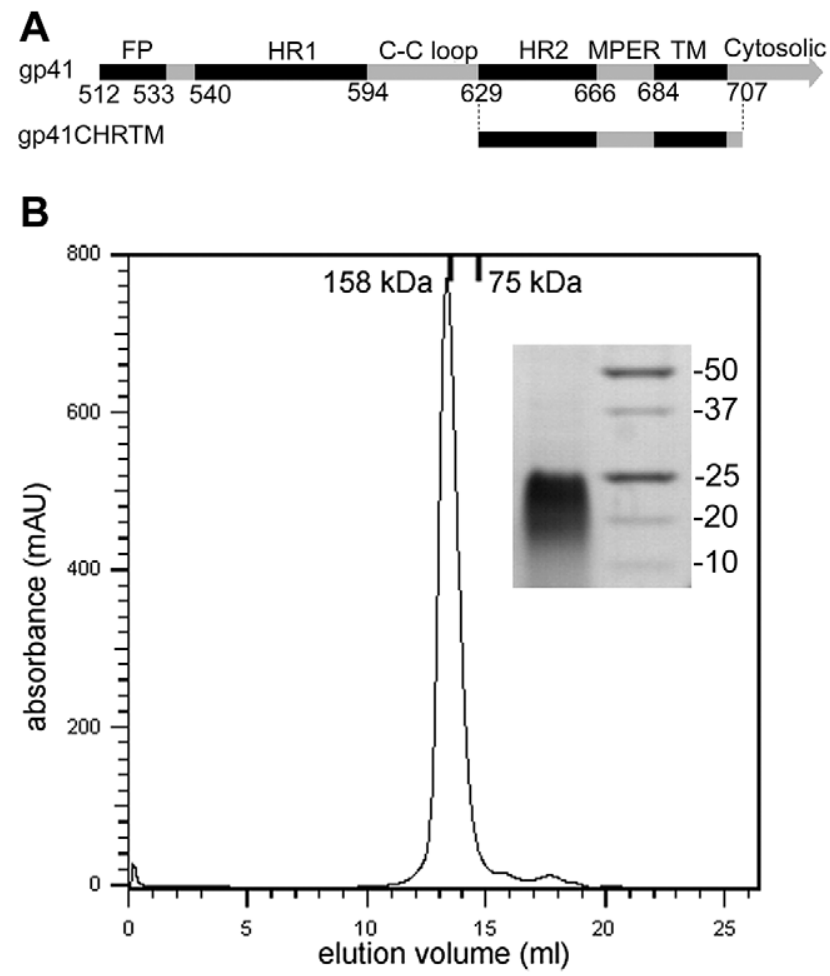

Figure 1. The gp41CHRTM antigen used for immunization. A) Schematic representation of gp41 and of the regions present in gp41CHRTM. FP, fusion peptide; HR1, N-terminal heptad repeat; C-C loop, cysteine loop, HR2, C-terminal heptad repeat; MPER, membrane proximal external region; TM, transmembrane region. The residue numbers at the domain/region boundaries are given. B) Gel filtration chromatogram of recombinant gp41CHRTM, which elutes at $13.3 \mathrm{ml}$ from the column, similar to the elution profile of a marker protein of $158 \mathrm{kDa}$. This indicates that gp41CHRTM is most likely trimeric and may have an elongated structure. The inset shows a Coomassie stained SDSPAGE gel with the gp41CHRTM protein band at the left and a protein marker at the right with the marker protein sizes in $\mathrm{kDa}$ indicated at the right.

doi:10.1371/journal.ppat.1003202.g001

and 2F5 Fab allowed the mapping of the 2H10 epitope and identified five residues (E657, Q658, L661, E662 and K665) important for $2 \mathrm{H} 10$ binding. Notably, three out of the five are part of the 2F5 epitope (Fig. 3A and 3B).

Next, we tested whether $2 \mathrm{H} 10$ recognizes its epitope in a helical conformation. To achieve this, the peptide sequence (residues 655-669) was fused to a short coiled-coil that was shown to favor a helical conformation of the fused sequences [103]. The fusion construct was designed in such a way that the $2 \mathrm{H} 10$ residues required for interaction are exposed. Binding assays demonstrated that $2 \mathrm{H} 10$ binding was unaffected when the MPER peptide was fused to the coiled-coil template (Fig. 3G). In contrast, 2F5, which binds its epitope in a $\beta$-hairpin conformation [24] shows a dramatically reduced binding to the coiled-coil MPER construct (Fig. 3D). Replacement of heptad positions by Gly, which are helix breakers and thus do not support a helical MPER conformation, further leads to the loss of $2 \mathrm{H} 10$ interaction (Fig. 3C).

$2 \mathrm{H} 10$ binding to Env and construction of bivalent $2 \mathrm{H} 10$

Because MPER antibodies primarily target the fusion intermediate state of gp41 [60,104,105], binding of $2 \mathrm{H} 10$ was tested to a soluble form of the fusion intermediate conformation of gp41, 
A

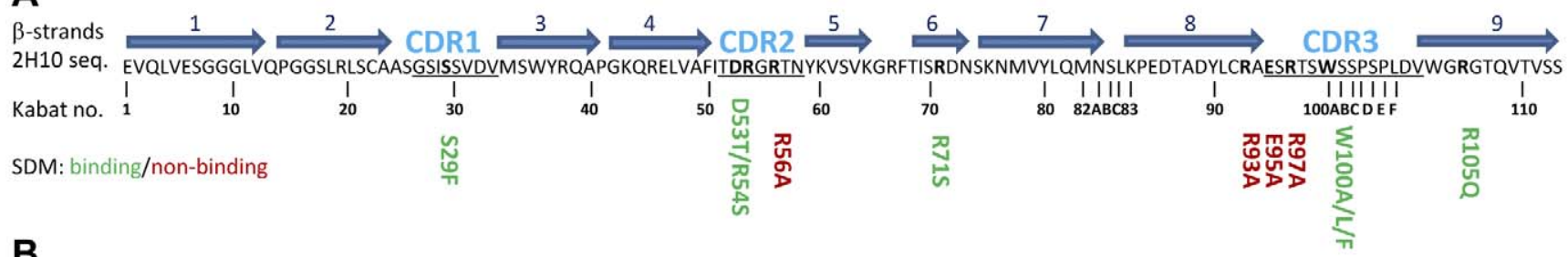

Germline

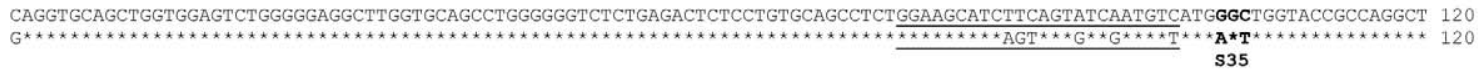

Germline

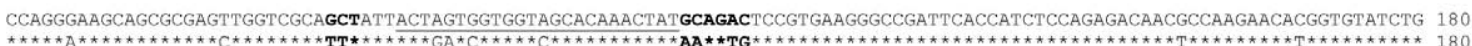

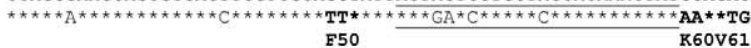

Figure 2. Amino acid and DNA sequence of $\mathbf{2 H 1 0 .}$ A) Amino acid sequence. Secondary structure assignment is based on the crystal structure. $\beta$-strands are depicted as blue arrows. CDR regions are indicated with CDR1 to CDR3 and are underlined. Residues depicted in bold were mutated. Mutants that still showed binding are shown in green and mutants that do not bind to the antigen anymore are shown in red. B) DNA sequence alignment of $2 \mathrm{H} 10$ with the germline $\mathrm{V}$-gene from which it originated. The asterisks indicate identical nucleotides. The CDR1 and CDR2 coding regions are underlined. Codons with at least two point mutations are in boldface.

doi:10.1371/journal.ppat.1003202.g002

gp41 INT [60]. SPR measurements revealed a $\mathrm{K}_{\mathrm{D}}$ of $29 \mathrm{nM}$ for the $2 \mathrm{H} 10$ monohead (Fig. S1A). The avidity increased substantially to $2.5 \mathrm{nM}$, when two $2 \mathrm{H} 10 \mathrm{VHH}$ were linked with a 15-GS linker (bi-2H10) (Fig. S1B). Surprisingly, 2H10 and bi-2H10 interacted with similar affinities of $18 \mathrm{nM}$ and $1.1 \mathrm{nM}$, respectively with gp41 $1_{523-883}$, a potential late fusion intermediate conformation [29] (Figs. S1C and S1D). In addition binding to gp140 from clade 92UG037 was recorded. 2H10 interaction with gp140 was fit with a two state reaction model, because an experiment with different injection durations with $2 \mathrm{H} 10$ indicated that it binds in two states, a low affinity followed by a high affinity state (Fig. S1E), which may be due to heterogeneous conformational states of gp41 present in recombinant gp140 consistent with the presence of nonnative Env on virions [106]. Again the affinity of $2 \mathrm{H} 10$ $\left(\mathrm{K}_{\mathrm{D}}=4 \mathrm{nM}\right)$ is inferior to bi-2H10 binding $\left(\mathrm{K}_{\mathrm{D}}=0.15 \mathrm{nM}\right)$, based on both the heterogeneous ligand fit and the two state reaction fit (Figs. S1F and S1G). In order to confirm the pepscan $2 \mathrm{H} 10$ binding to the linear gp4l peptide epitope, isothermal titration calorimetry was used to determine the affinity of $2 \mathrm{H} 10$ to linear and cyclic forms of peptide ${ }_{65}{ }_{\text {KNEQELLELDKWASL }} 69$. This revealed affinities of $35 \mathrm{nM}$ and $84 \mathrm{nM}$, respectively, indicating that cyclisation of the peptide epitope is unfavorable and reduces the binding affinity. However, the $\mathrm{K}_{\mathrm{D}}$ of $35 \mathrm{nM}$ is in good agreement with the SPR data and indicates that no other determinants of gp41 (present in gp41 int) contribute to binding. We next tested whether $2 \mathrm{H} 10$ interacts with wild type native Env expressed on the plasma membrane, which revealed no interaction with either cleaved or uncleaved forms of JR-FL Env comparable to the lack of significant 4E10 interaction (Fig. 4). We conclude that $2 \mathrm{H} 10$ interacts with a linear sequence with a helical conformation present in two gp4l conformations tested.

\section{Bi-2H10 neutralizes HIV-1}

The 2H10 VHH monohead did not neutralize any of the HIV1 strains tested (Table 1). However, bivalent 2H10, which showed an increased affinity for gp4l as compared to the monohead, was able to neutralize HIV-1 isolates and pseudoviruses in a TZM-bl assay. No substantial difference was observed for bi-2H10 with a 15 or 17 amino acid linker. The activity of bi-2H10 with the 17 amino acid linker (bi-17GS) was mainly directed towards clade B, neutralizing 14 of $26 \mathrm{~B}$ isolates, one clade A (i.e. 92UG037) and none of the clade $\mathrm{C}$ isolates due to the sequence conservation of the epitope. Eight strains neutralized are Tier 1 and seven are Tier 2 viruses. $\mathrm{Bi}-2 \mathrm{H} 10$ also neutralized both the neutralization sensitive and resistant variants of SHIV SF162 consistent with SF162.LS neutralization (Table 1). The IC50 values were between equal to and 100-fold lower than those of mAb 2F5, which neutralized 18 out of 23 clade B viruses tested (Table 1). Bi-2H10, like 2H10, did not interact with cell surface expressed JR-FL Env (Fig. 4), although the virus was neutralized. We conclude that that bi-2H10 acts downstream of receptor-induced conformational changes in Env and the increased avidity of bi-2H10 renders the VHH neutralization active.

\section{$2 \mathrm{H} 10$ exposes W100 at the tip of CDR3 which is required for neutralization}

To study the interaction of $2 \mathrm{H} 10$ with its epitope, several attempts were made to obtain crystals of $2 \mathrm{H} 10$ in complex with various MPER peptides based on the Pepscan analyses. However, in each attempt, diffraction quality crystals were obtained that contained the $\mathrm{VHH}$, but not the peptide. The best $2 \mathrm{H} 10$ containing crystals diffracted to $1.3 \AA$ resolution and the structure was solved by molecular replacement (Table 2). The structure resembles the framework of known VHH structures [76], with the major exception that most other $\mathrm{VHH}$ structures have CDR3 loops that fold back on the framework of the $\mathrm{VHH}$, whereas the CDR 3 of $2 \mathrm{H} 10$ protrudes from the framework of $2 \mathrm{H} 10$. However, it should be noted that its orientation may have been influenced by crystal contacts. Its most notable feature is the exposure of W100 at the tip of CDR3 (Fig. 5A). CDR3 W100 resembles the presence of hydrophobic residues within the CDR 3 heavy chains of $2 F 5$ and $4 \mathrm{E} 10$ [24,25], which are not essential for epitope interaction although changes in affinity have been reported depending on the nature of the antigen for some mutants. In contrast, mutations of hydrophobic CDR3 residues affect the neutralization potency of these antibodies dramatically [48-50]. Similarly, several $2 \mathrm{H} 10$ W100 mutants (i.e. W100A, W100F and W100L) interacted with gp $41_{\text {INT }}$ and gp140 with affinities comparable to wild type $2 \mathrm{H} 10$ (Fig. 6A and Fig. S1H), confirming that W100 is non-essential for epitope interaction. To study whether W100 is required for 


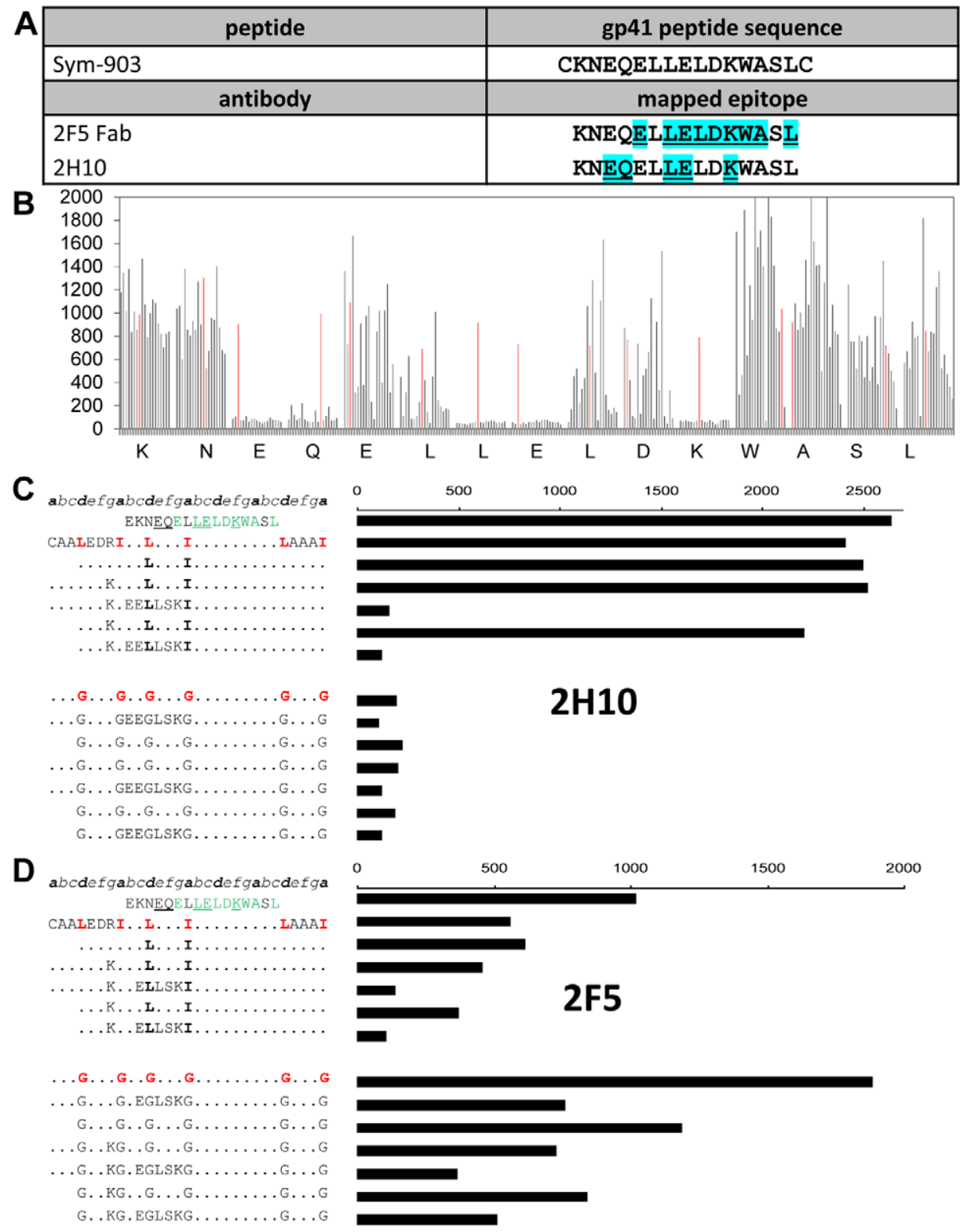

Figure 3. Epitope mapping of $\mathbf{2 H 1 0}$ and binding to helical peptides. A) The peptide Sym-903 was used for the replacement analysis with $2 \mathrm{~F} 5$ and $2 \mathrm{H} 10$. Underlined cyan colored residues are recognized by the antibodies. B) Full substitution analysis of $2 \mathrm{H} 10$ epitope on gp41 MPER. The binding activity of $\mathrm{VHH} 2 \mathrm{H} 10$ at $2 \mathrm{ng} / \mathrm{ml}$ with a peptide is shown as a vertical line proportional to the Pepscan ELISA signal. Each group of 19 lines corresponds to the replacement set of all residues except cysteine for each amino acid position in the original 15-mer cyclic peptide: KNEQELLELDKWASL. Within each group of 19 lines the substitutions are in alphabetical order: based on the one-letter amino acid code (ADEFGHIKLMNPQRSTVWY) and the reactivity of the original nonapeptide is shown as a red line. The peptides contained an N- and C-terminal cysteine and were cyclised by addition of a T2-CLIPS [115]. These results show that EQ at position 3 and 4 and LE at position 7 and 8 and K at position 11 , cannot be replaced by another amino acid without loss of binding and are thus essential for binding $2 \mathrm{H} 10$. C) Binding of VHH $2 \mathrm{H} 10$ (100 $\mathrm{ng} / \mathrm{ml})$ and D) Mab 2F5 (1 ng/ml) to gp41-MPER peptides grafted in GCN4-like helical templates that contain a stabilizing lle/Leu heptad repeat (top panel) and binding to peptides in which the zipper motif is mutated to destabilizing glycine residues (lower panel). Peptide sequences are all based on hybrids of HIV-1 gp41 and GCN4. Alignment is shown of peptide sequence with heptad repeat positions (top line). Residues essential for $2 \mathrm{H} 10$ binding according to the substitution analysis are underlined and residues essential for 2F5 binding are in green. Mutations are shown with one-letter codes and dots indicated that the residue is not changed.

doi:10.1371/journal.ppat.1003202.g003

neutralization, the W100A mutation was introduced into bi-2H10 (bi-2H10-W100A). SPR confirmed that bi-2H10-W100A binds to gp140 comparable to wild type bi-2H10 revealing the same dissociation rate together with a slightly slower on-rate (Fig. 6B). Although not essential for gp41 interaction, the exchange of W100 to alanine completely abrogated neutralization of most strains. Four other strains tested showed a reduced potency as evident from the 4-and 6-fold increased IC50 values for these viruses (Table 1). In addition, bi-2H10 W100A did not interact with surface-expressed Env as expected (Fig. 4). We thus conclude that CDR3 W100 is dispensable for epitope interaction but is essential for neutralization similar to the role of hydrophobic CDR3 heavy chain residues present in mAbs $2 \mathrm{~F} 5$ and $4 \mathrm{E} 10$ [48-50]. In order to map the gp41 binding site on $2 \mathrm{H} 10$ the following mutants (S29F, 
A

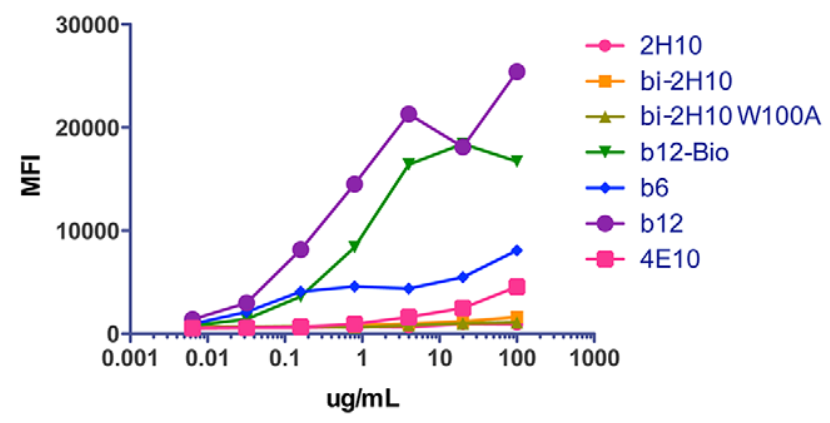

B

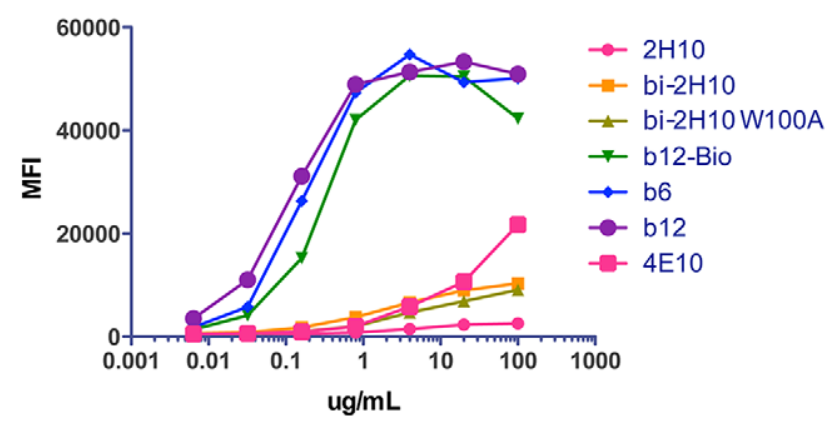

Figure 4. $2 \mathrm{H} 10, \mathrm{bi}-2 \mathrm{H} 10$ and bi-2H10 W100A do not interact with membrane anchored Env. FACS analysis of HEK293T cells transfected with JR-FL Env in its cleaved (A) and un-cleaved form (B). The increase in mean fluorescence intensity (MFI) has been blotted as a function of antibody concentration. Control antibodies include b12, b6, b12-Bio (biotinylated version of B12) and 4E10. The lack of significant b6 interaction with the cells expressing cleaved Env indicates that most Env has been processed.

doi:10.1371/journal.ppat.1003202.g004

D53T/R54S，R54S，R56A，R71S，R93A，E95A，R97A) were designed based on the structure (Fig. 5A) and the VHH germline sequence of CDR1 and CDR2 (Fig. 2). Assessment of binding by SPR revealed that the single mutants R56A, R93A, E95A, and R97A lost binding to gp140-92UG037 (Fig. 6A). All other mutants (S29F, D53T/R54S, R54S, R71S) still bound gp140, although the affinities for some seemed to be marginally lower than for wildtype $2 \mathrm{H} 10$. This thus implicates the charged residues $\mathrm{R} 56$ in CDR2 and R93, E95 and R97 of CDR3 in gp41 recognition.

Because it was reported that mAbs $2 \mathrm{~F} 5$ and $4 \mathrm{E} 10$ have lipid binding activity, we tested whether $2 \mathrm{H} 10$ also binds liposomes or lipids. Sucrose gradient flotation analyses showed that $2 \mathrm{H} 10$ does not float with liposomes having the lipid composition of native $\mathrm{HIV}-1$ virions. $2 \mathrm{H} 10$ is only found in the bottom fractions of the gradient while a substantial amount of $4 \mathrm{E} 10$ floats to the upper fraction of the gradient in this assay. However, $2 \mathrm{~F} 5$ did not reveal any liposome binding either (Fig. S2A). This is consistent with ELISA data which demonstrated binding of mAb $4 \mathrm{E} 10$ to cardiolipin and phosphatidylserine, while $2 \mathrm{H} 10$, bi-2H10 and 2 F5 revealed no binding activity (Fig. S2B). We conclude that 2H10 exerts no measurable lipid binding activity.

2H10-gp41 complex formation: NMR characterization of $2 \mathrm{H} 10$ in the free and peptide-bound form

${ }^{15} \mathrm{~N}$ HSQC spectra of $2 \mathrm{H} 10$ were recorded in the absence or presence of an excess of the gp41 peptide and revealed a sufficient spectral resolution to allow the $1 \mathrm{H}, 15 \mathrm{~N}$, and $13 \mathrm{C}$ backbone assignment of the two forms using heteronuclear experiments (Fig. S3). Chemical shift index (CSI) calculated from the CB, CA, N and $\mathrm{CO}$ chemical shifts reveal similar secondary structures for the free and the bound forms (Fig. S4). The specific shift of individual residues was observed using ${ }^{15} \mathrm{~N}$ HSQG spectra recorded at different ratios of gp4l peptide to $2 \mathrm{H} 10$ and depend on the peptide concentration (Fig. 5B). These data reveal a slow exchange process between the bound and the free form in agreement with the affinity constant measured for this complex. The complete list of chemical shift differences (CSD) induced in 2H10 upon peptide binding is listed in Figure S5 (Fig. S5), which confirmed further that peptide binding, did not induce conformational changes in the tertiary structure of $2 \mathrm{H} 10$. Notably most significant CSDs map to one surface of the $2 \mathrm{H} 10$ structure providing a first clue on the gp41 ligand position (Fig. 5C).

\section{Modeling of the $2 \mathrm{H} 10$ gp41 peptide complex}

Modeling of the $2 \mathrm{H} 10$ interaction with a helical gp41 peptide conformation with HADDOCK [97] readily produced a top cluster with an average cluster score significantly lower than any other solution $(-96.3 \pm 0.5$ a.u.). This cluster corresponded also to the most populated one with 173 members out of 200 models generated. Its electrostatic energy is $-437.0 \pm 31.1 \mathrm{kcal} / \mathrm{mol}$ and its Van der Waals energy $-36.9 \pm 6.9 \mathrm{kcal} / \mathrm{mol}$. The model reveals that the short gp41 helix binds in a parallel fashion to the $2 \mathrm{H} 10$ beta-sheet involving a network of salt bridges (E654-K60; K665-E95; D664-R56) and hydrogen bonds (E654-Q44; E657S62 amide; Q658-amide-L47; E662-Y37; R96-L669 carbonyl). In addition, R93 stabilizes the orientation of Y36 and E95, which contact E662 and K665, respectively (Fig. 7A). The network of interactions is consistent with the chemical shift perturbation (Fig. 5B) and mutagenesis data, which implicate R56, R93, E95 and R97 in the interaction. CDR3 S99 and S100D show additional chemical shift differences upon peptide binding. This may indicate that the CDR3 may be flexible enough to contact the peptide or alternatively, that peptide binding induces major changes within the CDR3 conformation or orientation. Among the interacting residues are five of the six framework residues that deviate from the germline (S35, F50, K60, V61 and R93) by at least two nucleotide changes in their codons (Fig. 2B). The sixth residue (L91) is very close to the interaction site. Their occurrence in $\mathrm{VHH}$ is rather rare ( $\mathrm{F} 50,1.5 \%$ of $\mathrm{VHH}$ sequences, $\mathrm{K} 60,0.8 \%$, V61, $0.7 \%$ and R93, $0.52 \%$ of VHH sequences (https://fungen. wur.nl/). The model also corroborated that CDR3 W100 does not interact with gp41. Subsequent superpositioning of the $\mathrm{C} \alpha$ atoms of the VHH-peptide model (Fig. 7A) and the trimeric structure of the late fusion intermediate [29] yielded a trimer model without any clashes (Fig. 7B). Importantly, it revealed that the side chain of W100 is positioned in such a way that it could dip into the membrane bilayer in the same plane as gp41 MPER residues W678, W680 and Y681 (Fig. 7B). The latter have been proposed to insert into the membrane during the conformational changes of gp41 leading to membrane fusion [29]. We conclude that $2 \mathrm{H} 10$ binds a helical epitope of gp41, which allows positioning of the CDR3 W100 towards the membrane. Due to the small size of the VHH, 2H10 may stay associated with gp4l until late stages of membrane fusion.

\section{Discussion}

The HIV-1 envelope fusion subunit gp41 contains highly conserved epitopes within its MPER that are recognized by the potent and broadly neutralizing antibodies $2 \mathrm{~F} 5$ and $4 \mathrm{E} 10$. 
Table 1. $2 \mathrm{H} 10$, bivalent $2 \mathrm{H} 10$ and mutant bi-2H10 IC50 titers against HIV-1 in TZM-bl cells.

\begin{tabular}{|c|c|c|c|c|c|c|c|c|c|c|}
\hline \multirow[b]{2}{*}{ HIV-1/SHIV strain } & \multirow[b]{2}{*}{ Type } & \multirow[b]{2}{*}{ Clade } & \multirow[b]{2}{*}{ Tier } & \multirow[b]{2}{*}{$\begin{array}{l}\text { Accession } \\
\text { code }\end{array}$} & \multirow[b]{2}{*}{ Epitope sequence } & \multicolumn{5}{|c|}{ IC50 $(\mu \mathrm{g} / \mathrm{ml})$} \\
\hline & & & & & & $2 \mathrm{H} 10$ & bi-15GS & bi-17GS & $\begin{array}{l}\text { W100A bi- } \\
\text { 15GS }\end{array}$ & $2 \mathrm{F5}$ \\
\hline HXB2 & PV & B & 1 & K03455 & EQELLELDK & & & & & \\
\hline BaL.26 & PV & B & 1 & DQ318211 & EQELLELDK & - & 6.9 & 11 & - & 10 \\
\hline SS1196.1 & PV & B & 1 & AY835442 & EQELLELDK & - & 13.5 & 13 & - & 15.5 \\
\hline NL4_3 & PV & B & 1 & U26942 & EQELLELDK & - & 4.4 & 0.2 & - & 0.087 \\
\hline IIIB & TCLA & B & 1 & EU541617 & EQEELLELDK & - & 9.0 & 15.7 & - & 0.4 \\
\hline AC10.0.29 (SVPB13) & PV & B & 2 & AY835446 & EQELLALDK & - & & - & & 4.4 \\
\hline RHPA4259.7 (SVPB14) & PV & B & 2 & AY835447 & EQELLALDK & - & & - & & 13.46 \\
\hline SF162.LS & PV & B & $1 a$ & EU123924 & EQEELLELDK & - & 49.02 & & - & 1.77 \\
\hline $\mathrm{MN}-3$ & PV & B & 1 & AY669737 & EQELLELDK & - & 0.78 & & 4.80 & $<0.02$ \\
\hline JR-FL.JB & PV & B & 2 & AY669728 & EQEELLELDK & - & 2.42 & & 15.01 & 3.52 \\
\hline 6535.3 & PV & B & 2 & AY835438 & ELELLELDK & - & - & & - & 5.86 \\
\hline WITO4160.33 & PV & B & 2 & AY835451 & ELELLELDK & - & - & & - & 1.05 \\
\hline TRJO4551.58 & PV & B & 3 & AY835450 & ELELLKLDQ & - & - & & - & - \\
\hline REJO4541.67 & PV & B & 2 & AY835449 & EQELLELDK & - & - & & - & 1.04 \\
\hline PVO.4 & PV & B & 3 & AY835444 & $\underline{\text { EQ}}$ DLLALDK & - & - & & - & - \\
\hline TRO.11 & PV & B & 2 & AY835445 & EQELLELDS & - & - & & - & - \\
\hline CAAN5342.A2 & PV & B & 2 & AY835452 & EKELLEELDK & - & - & & - & 10.11 \\
\hline THRO4156.18 & PV & B & 2 & AY835448 & EKELLEELDK & - & 33.48 & & - & - \\
\hline QH0692.42 & PV & B & 2 & AY835439 & $\underline{\text { EHELLELDK }}$ & - & 14.35 & & - & 1.01 \\
\hline SC422661.8 & PV & B & 2 & AY835441 & EQELLELDKK & - & & 10.8 & & \\
\hline SHIV SF162P4 & PV & B & 1 & M65024 & EQELLELDK & - & & 29.3 & & \\
\hline SHIV SF162P3 & PV & B & 2 & AY988107 & EQEELLELDK & - & & 4.4 & & \\
\hline WEAU-d15.410.787 & PV & $\mathrm{B}(\mathrm{T} / \mathrm{F})$ & 2 & EU289202 & EQELLELDK & - & 4.76 & & 17.21 & 0.59 \\
\hline 1006-11.C3.1601 & PV & $B(T / F)$ & 2 & EU289183 & $\underline{E L E L L A L D K}$ & - & - & & - & 1.99 \\
\hline 1054-07.TC4.1499 & PV & $\mathrm{B}(\mathrm{T} / \mathrm{F})$ & 2 & EU289185 & EKELLEELDK & - & - & & - & - \\
\hline 1056-10.TA11.1826 & PV & $B(T / F)$ & 1B & EU289186 & EQEELLELDK & - & 28.9 & & - & 0.26 \\
\hline 1012_11_TC21_3257 & PV & $\mathrm{B}(\mathrm{T} / \mathrm{F})$ & $1 \mathrm{~B}$ & EU289184 & EKELLELELK & - & - & & - & 0.91 \\
\hline 92UG037.A9 & MC & A & ND & AB253429 & EKDLLELDKK & - & 2.4 & 28 & - & \\
\hline 92UG0378 & PV & A & 2 & AB253429 & $\underline{\text { EKDLLEELDK }}$ & - & 4.66 & & 18.69 & 0.60 \\
\hline Q23.17 & PV & A & ND & AF004885 & EKELLEELDK & - & - & & - & 4.97 \\
\hline Q769.d22 & PV & A & 2 & AF407158 & EQQDLLALDK & - & - & & - & 4.92 \\
\hline 0330.v4.c3 & PV & A & ND & HM215257 & EQQDLLALDK & - & - & & - & 14.10 \\
\hline ZM249M.PL1 & PV & c & 2 & FJ496214 & EKDLLEELDS & - & - & & - & - \\
\hline ZM135M.PL10a & PV & C & 2 & AY424079 & EKDLLALDS & - & - & & • & - \\
\hline ZM53M.PB12 & PV & c & 2 & AY423984 & EKDLLALDS & - & - & & - & - \\
\hline 93MW965.26 & PV & c & 1 & U08455 & EKDLLALDS & - & & - & & \\
\hline 96ZM651.02 & PV & c & 2 & AF286224 & EKDLLALDS & - & & - & & - \\
\hline ZM 109F.PB4 & PV & C & 2 & AY424138 & EKELLALNNK & - & & - & & \\
\hline
\end{tabular}

Neutralization activities of $2 \mathrm{H} 10$, bivalent $2 \mathrm{H} 10$, W100A mutant bi-2H10 and as a control $2 \mathrm{~F} 5$ were determined against the indicated viruses. The type, clade, tier and the accession code of the envelope protein sequence are given for each virus strain. The wild-type bi-2H10s are named bi-15GS and bi-17GS and have a 15 and 17 residue linker respectively. The W100A mutant bi-2H10 is named W100A bi-15GS and has a 15 residue linker. The column labeled Tier indicates whether the virus is classified for 1,2, or 3 assessment of neutralizing antibodies [116]. The column labeled Epitope sequence, shows the sequence that aligns with the part of the HBX2 sequence to which $2 \mathrm{H} 10$ is directed. The underlined, boldfaced residues are essential for the binding of $2 \mathrm{H} 10$ and are equal to the residues at the equivalent positions in HXB2, which was used for immunization. Residues in grey are at the position of an essential residue, but deviate from the HBX2 equivalent. • indicates IC50>50 $\mu \mathrm{g} / \mathrm{ml}$; the empty cells represent non-performed measurements.

doi:10.1371/journal.ppat.1003202.t001

Although these bnAbs recognize linear epitopes, immunization with gp4l peptides or proteins has not yet produced such antibodies [107]. In this study, we isolated and characterized a VHH from a llama immunized with gp4l proteoliposomes.
Similar gp41 proteoliposomes, with a different liposome formulation and gp4l construct, used in a previous immunization study of mice using a different immunization strategy, yielded sera with no significant neutralization [37]. The $\mathrm{VHH} 2 \mathrm{H} 10$ recognizes an 
A

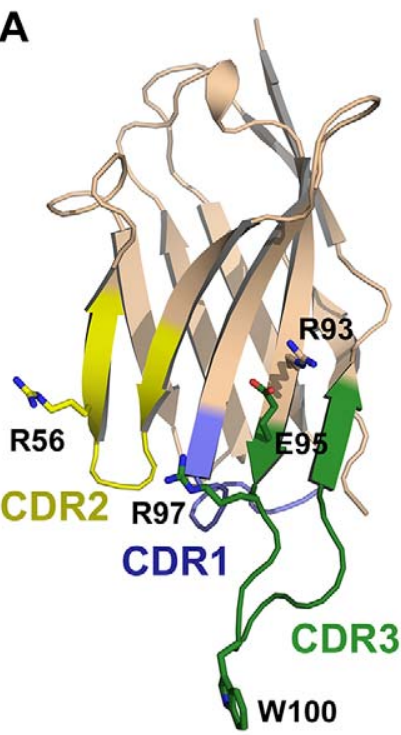

C

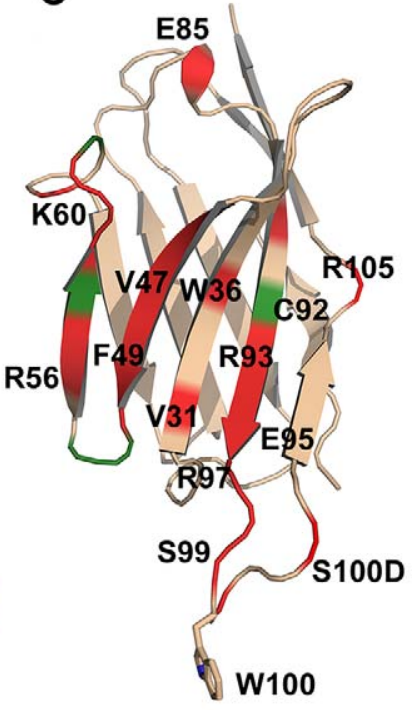

B

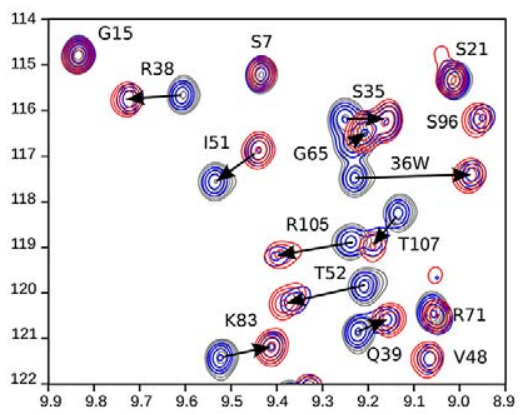

Figure 5. Crystal structure of $2 \mathrm{H} 10$ and NMR analysis of $\mathbf{2 H 1 0}$ interaction with the gp41 peptide. A) Ribbon representation of $2 \mathrm{H} 10$. CDR 1, 2 and 3 are colored blue, yellow and green, respectively. Residues implicated in gp41 interaction by mutagenesis are shown as sticks. W100 at the tip of CDR3 is required for neutralization. B) Selected region of the ${ }^{15} \mathrm{~N}$ HSQC spectra (see Fig. S3) recorded on a ${ }^{13} \mathrm{C}_{1}^{15} \mathrm{~N}$ labeled $2 \mathrm{H} 10$ sample. Increasing concentrations of the gp41 peptide were titrated into the $2 \mathrm{H} 10$ solution and induced specific chemical shifts; spectra were recorded with a protein:peptide ratio of 1:0, in grey, 1:0.5 in blue and 1:1 in red.C) Chemical shift perturbations (CSPs) were mapped onto the $2 \mathrm{H} 10$ structure. Residues showing ${ }^{15} \mathrm{~N},{ }^{1} \mathrm{H}$ chemical shift perturbations greater than $0.15 \mathrm{ppm}$ are shown in red and residues with an amide resonance disappearing in the free or the bound form are colored in green.

doi:10.1371/journal.ppat.1003202.g005

epitope (EQELLELDK) that partially overlaps with the 2F5 epitope $[20,24]$ and binds to its epitope present in various Env conformations with low nanomolar affinity.

One hypothesis is that neutralizing antibodies directed against MPER target epitopes that are only transiently exposed during the entry process $[60,104]$. Consequently their binding to the native Env structure may be weak, as demonstrated for mAb 2F5, which interacts only with few Env gp140 oligomers [60] and the absence of significant binding of MPER antibodies to membrane-anchored Env with the exception of 10E8 [9]. Because neither monomeric $2 \mathrm{H} 10$ nor bi-2H10 interacted with cleaved or uncleaved JR-FL Env, we hypothesize that their target is an Env conformation induced by receptor binding. In contrast $2 \mathrm{H} 10$ binds to recombinant Env gp140 derived from strain 92UG037. Binding of $2 \mathrm{H} 10$ is best described by a two-state reaction of a low affinity
A

2H10 mutants

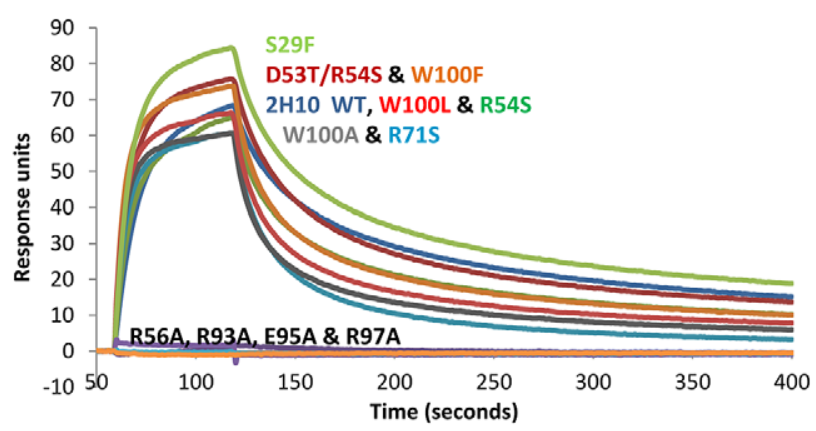

B bi-2H10 Trp mutant

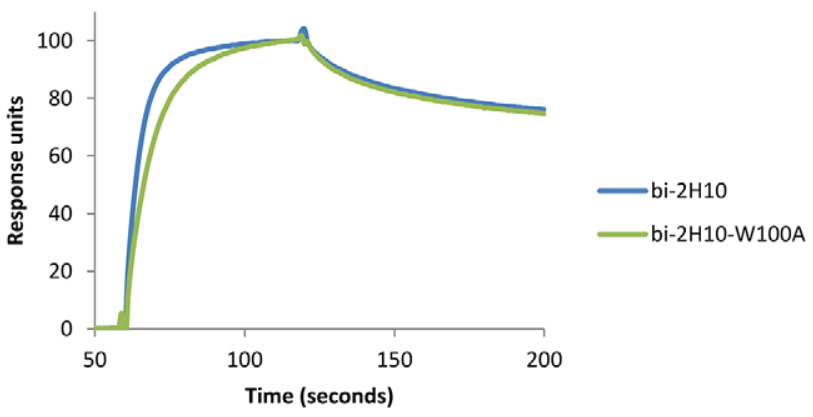

Figure 6. Surface plasmon resonance affinity measurements reveal essential and non-essential $2 \mathrm{H} 10$ residues for gp41 interaction. A) $2 \mathrm{H} 10$ single domain mutants. The curves are labeled with the mutant codes in colors corresponding with the colors of the curves. The mutants R56A, R96A, E98A and R100A do not bind at all to gp140-92UG037. Fitting the curves with the two-state reaction algorithm yielded $\mathrm{K}_{\mathrm{D}} \mathrm{S}$ of $8.0 \mathrm{nM}$ for $2 \mathrm{H} 10 \mathrm{WT}$ and $10.1 \mathrm{nM}$ for $2 \mathrm{H} 10-$ W100A. The other fits, except for those of the non-binding mutants, yielded $\mathrm{K}_{\mathrm{D}} \mathrm{s}$ between $5.5 \mathrm{nM}$ for $2 \mathrm{H} 10-\mathrm{S} 29 \mathrm{~F}$ and $18.7 \mathrm{nM}$ for $2 \mathrm{H} 10-\mathrm{R} 71 \mathrm{~S}$ B) bi-2H10-W100A mutant and wild type bi-2H10 on immobilized gp140-92UG037. Because the maximum responses units are slightly different for the two bi-2 $\mathrm{H} 10$ molecules, the curves were normalized to the maximum response, to be able to compare the dissociation rates well.

doi:10.1371/journal.ppat.1003202.g006

contact followed by a high affinity interaction. Thus $2 \mathrm{H} 10$ may induce its epitope in the soluble version of gp140, which may be facilitated by the fact that the C-terminal end of this recombinant gp140 protein is not constrained by the transmembrane region. Due to the potentially transient nature of the 2H10-epitope exposure, we tested binding to a soluble form of the fusion intermediate conformation of gp41, gp41 INT [108]. SPR measured a $30 \mathrm{nM}$ affinity for $2 \mathrm{H} 10$ binding to gp $41_{\text {INT, which is }}$ approximately 30 times lower than the 2F5 Fab affinity for the fusion intermediate conformation of gp41 from strain 92UG037, 92UG-gp41-inter-Fd [60]. Bi-2H10 showed a more than tenfold increase in binding to gp $41_{\mathrm{INT}}$, but still a lower affinity when compared to the $\mathrm{K}_{\mathrm{D}} \mathrm{S}$ of $\mathrm{Fab}$ or $\mathrm{scFv}$ interactions of $2 \mathrm{~F} 5$ and $4 \mathrm{E} 10$ with 92UG-gp41-inter-Fd [60]. It is thus possible that the lower affinity of monovalent $2 \mathrm{H} 10$ for gp $41_{\text {INT }}$ may affect its neutralization capacity of any of the tested HIV-1/SHIV strains. However, increasing the affinity by an increased avidity as demonstrated for bi-2H10 led to the neutralization of selected strains including some Tier 2 viruses with IC50 values ranging from 0.2 to $49 \mu \mathrm{g} / \mathrm{ml}$, when using the stringent TZM-bl cell assay. 
Table 2. Data collection and refinement statistics.

\begin{tabular}{|c|c|c|}
\hline Space group & & 123 \\
\hline Cell dimensions & $a, b, c(\AA)$ & $89.95,89.95,89.95$ \\
\hline Wavelength $(\AA ̊)$ & & 0.9395 \\
\hline Resolution (̊̊) & & $25.00-1.3(1.3-1.37)$ \\
\hline Measured reflections & & 3427903 \\
\hline Unique reflections & & 38741 \\
\hline Rmerge & & $0.069(0.295)$ \\
\hline $\mid / \sigma l$ & & $6.1(2.2)$ \\
\hline Completeness (\%) & & $99.0(100.0)$ \\
\hline Redundancy & & $13.9(14.2)$ \\
\hline Wilson B factor $\left(\AA^{2}\right)$ & & 12.2 \\
\hline Rcryst ( $\mathrm{N}^{\circ}$ reflections) & & $0.14(29381)$ \\
\hline Rfree ( $\mathrm{N}^{\circ}$ reflections) & & 0.17 (1509) \\
\hline \multirow[t]{2}{*}{ No. atoms } & Protein & 4960 \\
\hline & Water & 172 \\
\hline \multirow[t]{2}{*}{$B$-factors } & Protein & 32.32 \\
\hline & Water & 33.89 \\
\hline \multirow[t]{2}{*}{ R.m.s deviations } & Bond lengths $(\AA)$ & 0.005 \\
\hline & Bond angles $\left({ }^{\circ}\right)$ & 1.09 \\
\hline
\end{tabular}

Numbers in parentheses refer to the highest resolution shell. $R_{\text {merge }}=\Sigma\left|I_{-}\langle I\rangle\right|$ $\langle\Sigma \mid\rangle$, where $\mathrm{I}=$ observed intensity. $\mathrm{R}_{\text {cryst }}=\Sigma\left|\mathrm{Fo} \_\mathrm{Fc}\right| / \Sigma|\mathrm{Fo}|$, where $|\mathrm{Fo}|=$ observed structure factor. Amplitude and $|\mathrm{Fc}|=$ calculated structure factor amplitude. $R_{\text {free }}$ is $R_{\text {cryst }}$ for $3 \%$ of reflections excluded from the refinement.

doi:10.1371/journal.ppat.1003202.t002

Bi-2H10 may achieve HIV-1 entry inhibition by binding two gp41 molecules from the same trimer or cross link two gp4l trimers.

The crystal structure of the $2 \mathrm{H} 10 \mathrm{VHH}$ highlighted the longer than usual CDR3 that displays a solvent exposed tryptophan (W100) at its tip. Mutagenesis showed that W100 is not required for interaction with gp $41_{\text {INT }}$ or gp 140 . However, bi-2H10 with a W100A mutation either no longer neutralized or showed a largely reduced neutralization potency (increases of IC50 values $\sim 6$ - and 4-fold) against Tier 1 and Tier 2 strains despite its wild-type-like interaction with gp $41_{\text {INT }}$. The presence of W100 in the CDR3 of $2 \mathrm{H} 10$ is reminiscent of hydrophobic determinants within the CDR3 H3 regions of mAbs $2 \mathrm{~F} 5$ and 4E10, which are not required for gp4l interaction, but are important for neutralization activity [48-50]. In case of $\mathrm{mAb} 2 \mathrm{~F} 5$, single Ser substitutions resulted in a 15- to 500-fold reduction in neutralization potency, while double mutations to Ser completely abrogated 2F5-mediated neutralization [50]. Even though most HIV-1 strains were no longer neutralized by the bi-2H10 W100A mutant, it is conceivable that a W100 to Ser mutation may have been even more efficient in affecting neutralization due to the polar propensity of Ser. Similarly, single mutations in the CDR 3 of mAb $4 \mathrm{E} 10$ reduced its neutralization potency [48] and it was noted that Asp substitutions exerted a greater effect on neutralization potency than Ala substitutions [49]. The effect of the bi-2H10 W100A mutant also suggests that neutralization by bi-2H10 is not solely due to heteroligation of two antigen binding domains via an increased avidity [59,109]. We therefore propose that CDR3 W100 plays a crucial role in neutralization by bi-2H10, which resembles the role of the hydrophobic CDR3 of mAbs $2 \mathrm{~F} 5$ and $4 \mathrm{E} 10$ in neutralization.

Numerous studies suggested that the hydrophobic CDR3 residues are implicated in lipid/membrane interaction thereby facilitating
A
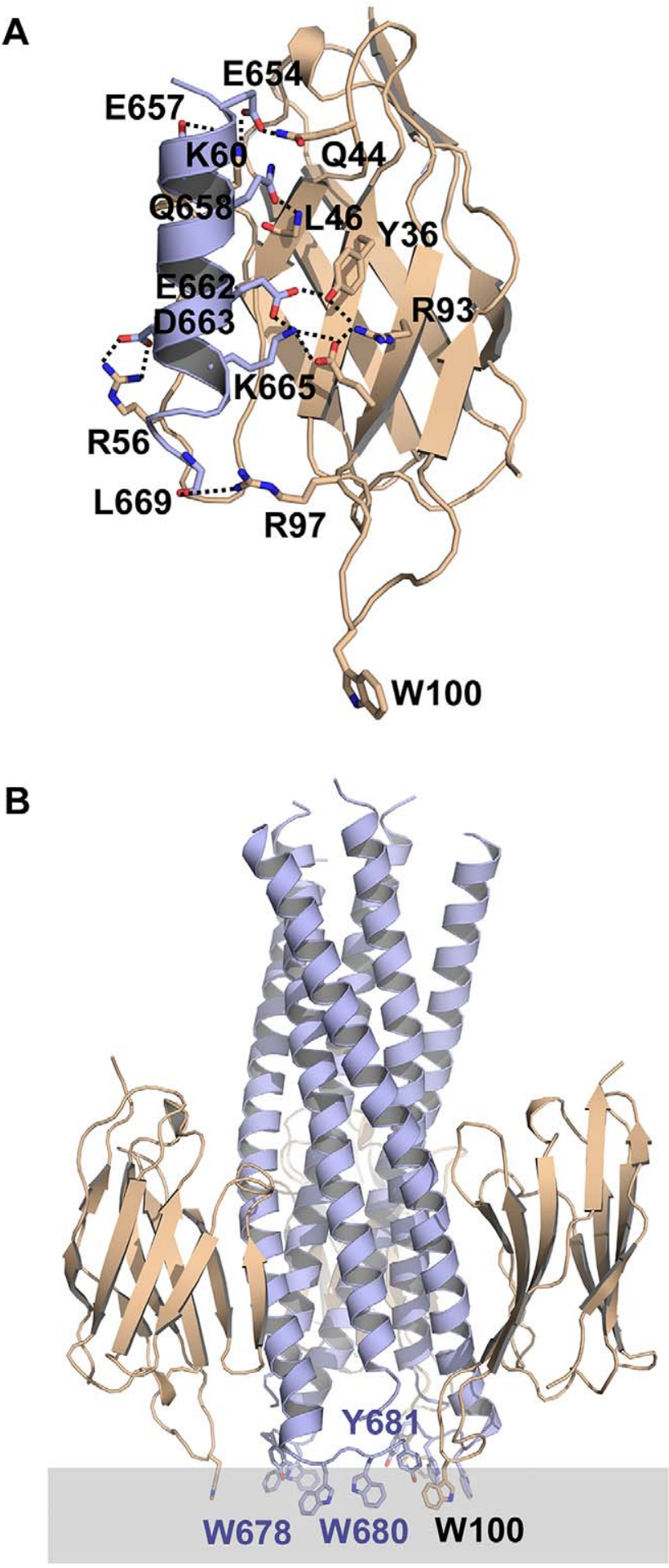

Figure 7. Molecular modeling of the 2H10-gp41 peptide interaction suggests that $2 \mathrm{H} 10 \mathrm{~W} 100$ is oriented towards the membrane. A) Molecular model of the gp41 peptide interaction with $2 \mathrm{H} 10$ produced by HADDOCK. Salt bridges and hydrogen bonds present in the top model and found in most of the top10 models are shown as dashed lines. B) Superpositioning of the $\mathrm{C} \alpha$ atoms of the gp41 peptide derived from the HADDOCK $2 \mathrm{H} 10$-peptide model onto the structure of a late fusion intermediate of gp41 [29] shows that the CDR3 W100 is oriented towards the membrane and found in the same plane as gp41 residues W678, W680 and Y681. Note that there are no clashes between the $2 \mathrm{H} 10 \mathrm{VHH}$ and gp41.

doi:10.1371/journal.ppat.1003202.g007 
antigen binding [46,110,111]. One possibility is that MPER itself becomes membrane-embedded during the fusion reaction and MPER-specific antibodies need to recognize their epitope within the membrane context $[52,112]$. We therefore presented MPER in a lipid bilayer context to allow selection of antibodies that can recognize lipid and protein determinants. However, despite the presence of W100 in CDR3, 2H10 as well as the control mAb 2F5 did not show any detectable lipid binding specificity in vitro.

All HIV-1 strains that were neutralized by bi-2H10 have the epitope sequence determined by pepscan analyses except for 92UG037.A9 which has Q658 replaced by a lysine. However, SPR measurements of $2 \mathrm{H} 10$ to gp140 env derived from 92UG037.A9 corroborate 2H10 binding. The discrepancy may be explained by the use of cyclic peptides in the pepscan analysis, which showed a lower affinity in the ITC experiment. Therefore a Q658K exchange may have had a larger effect on binding within the cyclic version than within natural contexts of the epitope. Sequence analysis of 2300 Env sequences revealed that $\sim 28 \%$ have the epitope 657-E(Q/K/H)-XX-LE-XX-K-665. Considering only $\mathrm{B}$ clades, the number of isolates covered would rise to $\sim 61 \%$. In comparison, $2 \mathrm{~F} 5$ and $4 \mathrm{E} 10$ have been shown to neutralize $68 \%$ and $97 \%$ of all clade B strains tested and $60 \%$ and $98 \%$ of all clades, respectively [1].

The combined structural approach using peptide modeling, NMR, docking and mutagenesis showed that $2 \mathrm{H} 10$ interacts with a helical linear gp41 epitope. VHH maturation played an important role in optimizing antigen binding, because somatic mutations involve both CDR and framework residues at the interaction site. High framework mutation rate has been observed in broadly neutralizing human antibodies as well [5-7,113]. The helical epitope conformation is present in the late fusion intermediate conformation of gp41, gp41 ${ }_{528-683}$ [29] that interacts with $2 \mathrm{H} 10$. This is unexpected, because 4E10 whose epitope is exposed and accessible in gp41 $1_{528-683}$ [29] does not interact with this conformation due to molecular clashes of the light chain with gp41 heptad repeat region 1 [29]. The fact that the small size of $2 \mathrm{H} 10$ allows binding to gp $41_{528-683}$ may constitute a disadvantage for using small llama $\mathrm{VHH}$ over complete antibodies; the $\mathrm{VHH}$ may thus less efficiently prevent refolding of gp41 into the six helical bundle post fusion conformation. Nevertheless, an interesting feature surfaced from the $2 \mathrm{H} 10$-gp $41_{528-683}$ complex model. The model poses $2 \mathrm{H} 10$ CDR3 W100 in the same plane as gp41 MPER residues W678, W680 and Y681, which may insert into the membrane during the fusion process [29]. This indirectly corroborates the hypothesis that the necessity of W100 for HIV-1 neutralization is in agreement with the suggestion that part of MPER may be membrane embedded. Because MPER, as observed in the late fusion-intermediate gp41 528-683 structure, may be already membrane-embedded at an earlier stage, anti-MPER antibodies such as 2H10 may act much earlier to block the fusion process. Alternatively, bi-2H10 binding may prevent membrane extraction of MPER, which is likely required to finalize membrane fusion [29].

The epitope of $2 \mathrm{H} 10$ overlaps with the helical epitope of $\mathrm{mAb}$ $13 \mathrm{H} 11$, which is, however, non-neutralizing due to the absence of a long hydrophobic heavy chain CDR3 [114]. The helical epitope of $2 \mathrm{H} 10$ is part of the helical epitope recognized by the broadly neutralizing anti-MPER mAb 10E8, isolated from a patient [9]. In this MPER conformation, which may represent the structure of MPER within native Env trimers, residues 656 to 683 form two short L-shaped helices of which the C-terminal helix provides most antibody binding contacts. Most notably, mAb 10E8 employs hydrophobic CDR 3 residues Phe 100A and W100B for interaction with its epitope. Because mAb 10E8 displays no autoreactivity it presents a new class of potent anti-MPER antibodies [9].
The VHH 2H10, which was elicited by gp41 proteoliposomes as antigen stresses the importance of a membrane component in generating anti-MPER neutralizing antibodies. Although there have been many attempts to generate neutralizing MPER-specific anti gp41 antibodies in animals, no protein-based immunization scheme has produced sera or antibodies that neutralized HIV-1 in the stringent TZM-bl assay $[16,17,107]$. In this study, we have demonstrated that it is possible to elicit anti-MPER antibodies that neutralize HIV-1 by employing proteoliposomes containing the native Env transmembrane region that may orient MPER optimally with respect to the lipid bilayer, which in turn is important for antibody neutralization [55]. Although bi-2H10 lacks the potency and breadth of 2F5, 4E10 or 10E8, optimization of the immunization protocol such as longer immunization schemes which may produce more extensive somatic mutations could yield antibodies with higher breadth and potency.

\section{Supporting Information}

Figure S1 SPR with 2 H10 and bi-2H10. The following ligands were immobilized on a were immobilized on a CM5 chip: gp41INT A), B) and H), gp41528-683 C) and D), and gp14092UG037 E), F) and G). Injections were performed with a range of 1 to $200 \mathrm{nM}$ for 150 seconds each on both gp41 constructs, while for the immobilized gp140-92UG037, 6.25, 25, 100 and $400 \mathrm{nM}$ for 60 seconds was used. The fitted curves are represented by black lines and the raw data are shown in color. The data were measured in triplicates and the curves superpose very well. A) Response for 2H10on gp41INT, fitted with separate association and dissociation (shown association fit). B) Response for bi-2H10 on gp41INT. The curves were fitted using 1:1 Langmuir model. C), D). Response for $2 \mathrm{H} 10$ and bi-2H10 on gp41528-683 fitted using 1:1 Langmuir model. E) Proof of two-state reaction of $2 \mathrm{H} 10$ binding to gp 140 on gp140-92UG037. Injections were performed with $100 \mathrm{nM} 2 \mathrm{H} 10$ with different injection durations. The curves were normalized to the maximum of obtained response units. The observation that the dissociation is dependent on injection duration indicates a two-state reaction binding. F) Response for 2H10 on gp140-92UG037. The curves were fitted with the two-state reaction algorithm. G) Response for bi-2H10 on gp140-92UG037. The curves were fitted with the heterogeneous ligand algorithm. H) Response for mutant 2H10-W100A on gp41INT, fitted with separate association and dissociation (shown association fit).

(TIF)

Figure S2 Lipid binding test of $2 \mathrm{H10}, 4 \mathrm{E} 10$ and $2 \mathrm{F5}$. A) Sucrose gradient centrifugation analyses of 2H10, 4E10 and 2F5. The top and bottom of the gradient are indicated; hc, heavy chain; lc, light chain. B) ELISA with cardiolipin and phosphatidylserine. Binding of 4E10, 2F5, 2H10 and bi-2GH10 are indicated. Left panel binding to cardiolipin; right panel, binding to posphatidylserine.

(TIF)

Figure S3 15N HSQG of $2 \mathrm{H10}$ without and with a 1.5fold excess of peptide. The spectra were acquired at $600 \mathrm{MHz}, \mathrm{T}=37 \mathrm{C}$. Protein concentration was $0.95 \mathrm{mM}$, in in $25 \mathrm{mM}$ HEPES buffer and $75 \mathrm{mM} \mathrm{NaCl}$ (pH 6.7).

(TIF)

Figure S4 Secondary structure propensity of the free and bound form of $2 \mathrm{H10}$ determined from $\mathrm{CB}, \mathrm{CA}, \mathrm{CO}$, $\mathbf{N}$ chemical shift analysis using the program TALOS+. The chemical shift index (CSI) value of 1 corresponds to $100 \%$ helical conformation propensity and a value of -1 corresponds to a $100 \% \beta$-strand conformation propensity.

(TIF) 
Figure S5 Histograms showing the value of the chemical shift difference (CSD) in $\mathbf{2 H 1 0}$ induced upon binding with the gp41 peptide (1.5 fold excess). Residue numbers are indicated on the $\mathrm{X}$ axis (residues for which CSD is missing are prolines. The green and pale green bars with an arbitrary height represent residues whose $\mathrm{NH}$ correlation is not present in the $15 \mathrm{~N}$ HSQC spectrum for the free and bound form of $2 \mathrm{H} 10$, respectively (probably because of conformation exchange broadening). The CSI analysis of the free and bound form of $2 \mathrm{H} 10$ show that upon addition of an excess of ligand, the secondary structure of the protein does not change.

(TIF)

\section{References}

1. Walker LM, Phogat SK, Chan-Hui PY, Wagner D, Phung P, et al. (2009) Broad and potent neutralizing antibodies from an African donor reveal a new HIV-1 vaccine target. Science; 326(5950): 285-9.

2. Scheid JF, Mouquet H, Feldhahn N, Seaman MS, Velinzon K, et al. (2009) Broad diversity of neutralizing antibodies isolated from memory B cells in HIVinfected individuals. Nature; 458(7238): 636-40.

3. Wu X, Yang ZY, Li Y, Hogerkorp CM, Schief WR, et al. (2010) Rational Design of Envelope Identifies Broadly Neutralizing Human Monoclonal Antibodies to HIV-1. Science; 329(5993): 856-61.

4. Zhou T, Georgiev I, Wu X, Yang ZY, Dai K, et al. (2010) Structural basis for broad and potent neutralization of HIV-1 by antibody VRC01. Science; 329(5993): 811-7

5. Corti D, Langedijk JP, Hinz A, Seaman MS, Vanzetta F, et al.(2010) Analysis of memory $\mathrm{B}$ cell responses and isolation of novel monoclonal antibodies with neutralizing breadth from HIV-1-infected individuals. PLoS One; 5(1): e8805.

6. Scheid JF, Mouquet H, Ueberheide B, Diskin R, Klein F, et al. (2011) Sequence and Structural Convergence of Broad and Potent HIV Antibodies That Mimic CD4 Binding. Science; 333(6049): 1633-7.

7. Wu X, Zhou T, Zhu J, Zhang B, Georgiev I, et al. (2011) Focused evolution of HIV-1 neutralizing antibodies revealed by structures and deep sequencing. Science; 333(6049): 1593-602.

8. Walker LM, Huber M, Doores KJ, Falkowska E, Pejchal R, et al. (2011) Broad neutralization coverage of HIV by multiple highly potent antibodies. Nature; 477(7365): 466-70.

9. Huang J, Ofek G, Laub L, Louder MK, Doria-Rose NA, et al. (2012) Broad and potent neutralization of HIV-1 by a gp41-specific human antibody. Nature; 491(7424): 406-12.

10. Kwong PD,Mascola JR (2012) Human Antibodies that Neutralize HIV-1: Identification, Structures, and B Cell Ontogenies. Immunity; 37(3): 412-425.

11. Kovacs JM, Nkolola JP, Peng H, Cheung A, Perry J, et al. (2012) HIV-1 envelope trimer elicits more potent neutralizing antibody responses than monomeric gp120. Proc Natl Acad Sci U S A; 109(30): 12111-6.

12. Sellhorn G, Kraft Z, Caldwell Z, Ellingson K, Mineart C, et al. (2012) Engineering, expression, purification, and characterization of stable clade A/B recombinant soluble heterotrimeric gp140 proteins. J Virol; 86(1): 128-42.

13. Sundling C, Forsell MN, O'Dell S, Feng Y, Chakrabarti B, et al. (2010) Soluble HIV-1 Env trimers in adjuvant elicit potent and diverse functional $\mathrm{B}$ cell responses in primates. J Exp Med; 207(9): 2003-17.

14. Feng Y, McKee K, Tran K, O'Dell S, Schmidt SD, et al. (2012) Biochemically defined HIV-1 envelope glycoprotein variant immunogens display differential binding and neutralizing specificities to the CD4-binding site. J Biol Chem; 287(8): 5673-86.

15. Kwong PD, Mascola JR, Nabel GJ (2011) Rational Design of Vaccines to Elicit Broadly Neutralizing Antibodies to HIV-1. Cold Spring Harb Perspect Med; 1(1): a007278.

16. McElrath MJ,Haynes BF (2010) Induction of Immunity to Human Immunodeficiency Virus Type-1 by Vaccination. Immunity; 33(4): $542-554$.

17. Walker LM,Burton DR (2010) Rational antibody-based HIV-1 vaccine design: current approaches and future directions. Current Opinion in Immunology; 22(3): 358-66.

18. Weissenhorn W, Hinz A, Gaudin Y (2007) Virus membrane fusion. FEBS Lett; 581(11): 2150-5.

19. Harrison SC (2008) Viral membrane fusion. Nat Struct Mol Biol; 15(7): 690698.

20. Muster T, Steindl F, Purtscher M, Trkola A, Klima A, et al. (1993) A conserved neutralizing epitope on gp41 of human immunodeficiency virus type 1.J Virol; 67(11): 6642-7.

21. Stiegler G, Kunert R, Purtscher M, Wolbank S, Voglauer R, et al.(2001) A potent cross-clade neutralizing human monoclonal antibody against a novel epitope on gp41 of human immunodeficiency virus type 1. AIDS Res Hum Retroviruses; 17(18): 1757-65.

22. Zwick MB, Labrijn AF, Wang M, Spenlehauer C, Saphire EO, et al. (2001) Broadly neutralizing antibodies targeted to the membrane-proximal external region of human immunodeficiency virus type 1 glycoprotein gp41. J Virol; 75(22): 10892-905.

\section{Acknowledgments}

We are grateful for the assistance of Rolf T. Urbanus with the design of the Biacore studies. We thank the Partnership for Structural Biology (PSB; http://www.psb-grenoble.eu) for access to the common platforms and the ESRF (Grenoble) staff for access and support at the beam lines.

\section{Author Contributions}

Conceived and designed the experiments: PP JPS RAW CTV WW LR. Performed the experiments: DLH YYL NMS SB LEM CS AH MH PM AMJJB JPML DD AFQ MMIAC MSS AR AF LR. Analyzed the data: DLH YYL SB MEK LEM AMJJB JPML DD AFQ MSS PP AF JPS WW LR. Wrote the paper: DLH YYL AMJJB JPS LEM CTV WW LR.

23. Nelson JD, Brunel FM, Jensen R, Grooks ET, Cardoso RM, et al. (2007) An affinity-enhanced neutralizing antibody against the membrane-proximal external region of human immunodeficiency virus type 1 gp 41 recognizes an epitope between those of 2F5 and 4E10. J Virol; 81(8): 4033-43.

24. Ofek G, Tang M, Sambor A, Katinger H, Mascola JR, et al. (2004) Structure and mechanistic analysis of the anti-human immunodeficiency virus type 1 antibody 2F5 in complex with its gp41 epitope. J Virol; 78(19): 10724-37.

25. Cardoso RM, Zwick MB, Stanfield RL, Kunert R, Binley JM, et al. (2005) Broadly neutralizing anti-HIV antibody 4E10 recognizes a helical conformation of a highly conserved fusion-associated motif in gp41. Immunity; 22(2): 163-73.

26. Pejchal R, Gach JS, Brunel FM, Cardoso RM, Stanfield RL, et al. (2009) A Conformational Switch in Human Immunodeficiency Virus gp41 Revealed by the Structures of Overlapping Epitopes Recognized by Neutralizing Antibodies. J Virol; 83(17): 8451-8462.

27. Weissenhorn W, Dessen A, Harrison SC, Skehel JJ, Wiley DC (1997) Atomic structure of the ectodomain from HIV-1 gp41. Nature; 387(6631): 426-30.

28. Chan DC, Fass D, Berger JM, Kim PS (1997) Core structure of gp41 from the HIV envelope glycoprotein. Cell; 89(2): 263-73.

29. Buzon V, Natrajan G, Schibli D, Campelo F, Kozlov MM, et al. (2010) Crystal Structure of HIV-1 gp41 Including Both Fusion Peptide and Membrane Proximal External Regions. PLoS Pathog; 6(5): e1000880.

30. Ferrantelli F, Hofmann-Lehmann R, Rasmussen RA, Wang T, Xu W, et al. (2003) Post-exposure prophylaxis with human monoclonal antibodies prevented SHIV89.6P infection or disease in neonatal macaques. Aids; 17(3): 301-309.

31. Mascola JR, Lewis MG, Stiegler G, Harris D, VanCott TC, et al. (1999) Protection of Macaques against pathogenic simian/human immunodeficiency virus 89.6PD by passive transfer of neutralizing antibodies. J Virol; 73(5): 400918.

32. Mascola JR, Stiegler G, VanCott TC, Katinger H, Carpenter CB, et al. (2000) Protection of macaques against vaginal transmission of a pathogenic HIV-1/ SIV chimeric virus by passive infusion of neutralizing antibodies. Nat Med; 6(2): 207-10.

33. Baba TW, Liska V, Hofmann-Lehmann R, Vlasak J, Xu W, et al. (2000) Human neutralizing monoclonal antibodies of the IgG1 subtype protect against mucosal simian-human immunodeficiency virus infection. Nat Med; 6(2): 2006.

34. Hofmann-Lehmann R, Vlasak J, Rasmussen RA, Smith BA, Baba TW, et al. (2001) Postnatal passive immunization of neonatal macaques with a triple combination of human monoclonal antibodies against oral simian-human immunodeficiency virus challenge. J Virol; 75(16): 7470-80.

35. Hessell AJ, Rakasz EG, Poignard P, Hangartner L, Landucci G, et al. (2009) Broadly Neutralizing Human Anti-HIV Antibody 2G12 Is Effective in Protection against Mucosal SHIV Challenge Even at Low Serum Neutralizing Titers. PLoS Pathog; 5(5): e1000433.

36. Mantis NJ, Kozlowski PA, Mielcarz DW, Weissenhorn W, Neutra MR (2001) Immunization of mice with recombinant gp41 in a systemic prime/mucosal boost protocol induces HIV-1-specific serum IgG and secretory IgA antibodies. Vaccine; 19(28-29): 3990-4001.

37. Lenz O, Dittmar MT, Wagner A, Ferko B, Vorauer-Uhl K, Stiegler G, Weissenhorn W (2005) Trimeric membrane-anchored gp41 inhibits HIV membrane fusion. J Biol Chem; 280(6): 4095-101

38. Qiao ZS, Kim M, Reinhold B, Montefiori D, Wang JH, Reinherz EL (2005) Design, expression, and immunogenicity of a soluble HIV trimeric envelope fragment adopting a prefusion gp41 configuration. J Biol Chem; 280(24): 23138-46.

39. Law M, Cardoso RM, Wilson IA, Burton DR (2007) Antigenic and immunogenic study of membrane-proximal external region-grafted gp120 antigens by a DNA prime-protein boost immunization strategy. J Virol; 81(8): 4272-85.

40. Phogat S, Svehla K, Tang M, Spadaccini A, Muller J, et al. (2008) Analysis of the human immunodeficiency virus type $1 \mathrm{gp} 41$ membrane proximal external region arrayed on hepatitis B surface antigen particles. Virology; 373(1): 72-84. 
41. Hinz A, Schoehn G, Quendler H, Hulsik DL, Stiegler G, et al. (2009) Characterization of a trimeric MPER containing HIV-1 gp41 antigen. Virology; 390(2): 221-7.

42. Ye L, Wen Z, Dong K, Wang X, Bu Z, et al. (2011) Induction of HIV Neutralizing Antibodies against the MPER of the HIV Envelope Protein by HA/gp41 Chimeric Protein-Based DNA and VLP Vaccines. PLoS One; 6(5): e14813.

43. Jain S, Patrick AJ, Rosenthal KL (2010) Multiple tandem copies of conserved gp41 epitopes incorporated in gag virus-like particles elicit systemic and mucosal antibodies in an optimized heterologous vector delivery regimen. Vaccine; 28(43): 7070-80

44. Dennison SM, Sutherland LL, Jaeger FH, Anasti KM, Parks R, et al. (2011) Induction of antibodies in rhesus macaques that recognize a fusionintermediate conformation of HIV-1 gp41. PLoS One; 6(11): e27824.

45. Zhou M, Kostoula I, Brill B, Panou E, Sakarellos-Daitsiotis M, et al. (2012) Prime boost vaccination approaches with different conjugates of a new HIV-1 gp41 epitope encompassing the membrane proximal external region induce neutralizing antibodies in mice. Vaccine; 30(11): 1911-6.

46. Haynes BF, Fleming J, St Clair EW, Katinger H, Stiegler G, et al. (2005) Cardiolipin polyspecific autoreactivity in two broadly neutralizing HIV-1 antibodies. Science; 308(5730): 1906-8.

47. Mouquet H, Scheid JF, Zoller MJ, Krogsgaard M, Ott RG, et al. (2010) Polyreactivity increases the apparent affinity of anti-HIV antibodies by heteroligation. Nature; 467(7315): 591-5.

48. Alam SM, Morelli M, Dennison SM, Liao HX, Zhang R, et al. (2009) Role of HIV membrane in neutralization by two broadly neutralizing antibodies. Proc Natl Acad Sci U S A; 106(48): 20234-9.

49. Scherer EM, Leaman DP, Zwick MB, McMichael AJ, Burton DR, et al. (2010) Aromatic residues at the edge of the antibody combining site facilitate viral glycoprotein recognition through membrane interactions. Proc Natl Acad Sci U S A; 107(4): 1529-34.

50. Ofek G, McKee K, Yang Y, Yang ZY, Skinner J, et al. (2010) Relationship between antibody $2 \mathrm{~F} 5$ neutralization of HIV-1 and hydrophobicity of its heavy chain third complementarity-determining region. J Virol; 84(6): 2955-62.

51. Julien JP, Huarte N, Maeso R, Taneva SG, Cunningham A, et al.(2010) Ablation of the complementarity-determining region $\mathrm{H} 3$ apex of the anti-HIV1 broadly neutralizing antibody $2 \mathrm{~F} 5$ abrogates neutralizing capacity without affecting core epitope binding. J Virol; 84(9): 4136-47.

52. Sun ZY, Oh KJ, Kim M, Yu J, Brusic V, et al. (2008) HIV-1 broadly neutralizing antibody extracts its epitope from a kinked gp41 ectodomain region on the viral membrane. Immunity; 28(1): 52-63.

53. Kim M, Sun ZY, Rand KD, Shi X, Song L, et al. (2011) Antibody mechanics on a membrane-bound HIV segment essential for GP41-targeted viral neutralization. Nat Struct Mol Biol; 18(11): 1235-43.

54. Guenaga J,Wyatt RT (2012) Structure-guided Alterations of the gp41-directed HIV-1 Broadly Neutralizing Antibody 2F5 Reveal New Properties Regarding its Neutralizing Function. PLoS Pathog; 8(7): e1002806.

55. Montero M, Gulzar N, Klaric KA, Donald JE, Lepik C, et al. (2012) Neutralizing Epitopes in the Membrane-Proximal External Region of HIV-1 gp41 Are Influenced by the Transmembrane Domain and the Plasma Membrane. J Virol; 86(6): 2930-41.

56. Chakrabarti BK, Walker LM, Guenaga JF, Ghobbeh A, Poignard P, et al. (2011) Direct antibody access to the HIV-1 membrane-proximal external region positively correlates with neutralization sensitivity. J Virol; 85(16): 821726.

57. Rathinakumar R, Dutta M, Zhu P, Johnson WE, Roux KH (2012) Binding of anti-membrane-proximal gp41 monoclonal antibodies to CD4-liganded and unliganded human immunodeficiency virus type 1 and simian immunodeficiency virus virions. J Virol; 86(3): 1820-31.

58. Ruprecht CR, Krarup A, Reynell L, Mann AM, Brandenberg OF, et al. (2011) MPER-specific antibodies induce gp120 shedding and irreversibly neutralize HIV-1. J Exp Med; 208(3): 439-54.

59. Klein JS, Gnanapragasam PN, Galimidi RP, Foglesong CP, West AP, et al. (2009) Examination of the contributions of size and avidity to the neutralization mechanisms of the anti-HIV antibodies b12 and 4E10. Proc Natl Acad Sci U S A; 106(18): 7385-90.

60. Frey G, Peng H, Rits-Volloch S, Morelli M, Cheng Y, et al. (2008) A fusionintermediate state of HIV-1 gp41 targeted by broadly neutralizing antibodies. Proc Natl Acad Sci U S A; 105(10): 3739-44.

61. Luftig MA, Mattu M, Di Giovine P, Geleziunas R, Hrin R, et al. (2006) Structural basis for HIV-1 neutralization by a gp41 fusion intermediatedirected antibody. Nat Struct Mol Biol; 13(8): 740-7.

62. Sabin C, Corti D, Buzon V, Seaman MS, Lutje Hulsik D, et al. (2010) Crystal structure and size-dependent neutralization properties of HK20, a human antibody binding to the highly conserved heptad repeat 1 of gp41. PLoS Pathogens; 6(11): e1001195.

63. Gustchina E, Li M, Louis JM, Anderson DE, Lloyd J, et al. (2010) Structural basis of HIV-1 neutralization by affinity matured Fabs directed against the internal trimeric coiled-coil of gp41. PLoS Pathog; 6(11): e1001182.

64. Shen X, Parks RJ, Montefiori DC, Kirchherr JL, Keele BF, et al. (2009) In Vivo gp41 Antibodies Targeting the 2F5 Monoclonal Antibody Epitope Mediate Human Immunodeficiency Virus Type 1 Neutralization Breadth. J Virol; 83(8): 3617-3625.
65. Zhu Z, Qin HR, Chen W, Zhao Q, Shen X, et al. (2011) Cross-reactive HIV1-neutralizing human monoclonal antibodies identified from a patient with 2F5-like antibodies. J Virol; 85(21): 11401-8.

66. Alam SM, Liao HX, Dennison SM, Jaeger F, Parks R, et al. (2011) Differential reactivity of germ line allelic variants of a broadly neutralizing HIV-1 antibody to a gp41 fusion intermediate conformation. J Virol; 85(22): 11725-31.

67. Morris L, Chen X, Alam M, Tomaras G, Zhang R, et al. (2011) Isolation of a human anti-HIV gp41 membrane proximal region neutralizing antibody by antigen-specific single B cell sorting. PLoS One; 6(9): e23532.

68. Alam SM, Scearce RM, Parks RJ, Plonk K, Plonk SG, et al. (2008) Human immunodeficiency virus type $1 \mathrm{gp} 41$ antibodies that mask membrane proximal region epitopes: antibody binding kinetics, induction, and potential for regulation in acute infection. J Virol; 82(1): 115-25.

69. Pietzsch J, Scheid JF, Mouquet H, Seaman MS, Broder CC, et al. (2010) Antigp41 antibodies cloned from HIV-infected patients with broadly neutralizing serologic activity. J Virol; 84(10): 5032-42.

70. Liao HX, Chen X, Munshaw S, Zhang R, Marshall DJ, et al. (2012) Initial antibodies binding to HIV-1 gp41 in acutely infected subjects are polyreactive and highly mutated. J Exp Med; 208(11): 2237-49.

71. Verkoczy L, Diaz M, Holl TM, Ouyang YB, Bouton-Verville H, et al. (2010) Autoreactivity in an HIV-1 broadly reactive neutralizing antibody variable region heavy chain induces immunologic tolerance. Proc Natl Acad Sci U S A; 107(1): 181-6.

72. Hamers-Casterman C, Atarhouch T, Muyldermans S, Robinson G, Hamers C, et al. (1993) Naturally occurring antibodies devoid of light chains. Nature; 363(6428): 446-8.

73. Forsman A, Beirnaert E, Aasa-Chapman MMI, Hoorelbeke B, Hijazi K, et al. (2008) Llama Antibody Fragments with Cross-Subtype Human Immunodeficiency Virus Type 1 (HIV-1)-Neutralizing Properties and High Affinity for HIV-1 gp120. J Virol; 82(24): 12069-12081.

74. Koh WW, Steffensen S, Gonzalez-Pajuelo M, Hoorelbeke B, Gorlani A, et al. (2010) Generation of a family-specific phage library of llama single chain antibody fragments that neutralize HIV-1. J Biol Chem; 285(25): 19116-24.

75. Jahnichen S, Blanchetot C, Maussang D, Gonzalez-Pajuelo M, Chow KY, et al. (2011) CXCR4 nanobodies (VHH-based single variable domains) potently inhibit chemotaxis and HIV-1 replication and mobilize stem cells. Proc Natl Acad Sci U S A; 107(47): 20565-70.

76. Hinz A, Lutje Hulsik D, Forsman A, Koh WW, Belrhali H, et al. (2010) Crystal structure of the neutralizing Llama $\mathrm{V}(\mathrm{HH})$ D7 and its mode of HIV-1 gp120 interaction. PLoS One; 5(5): e10482.

77. McCoy LE, Quigley AF, Strokappe NM, Bulmer-Thomas B, Seaman MS, et al. (2012) Potent and broad neutralization of HIV-1 by a llama antibody elicited by immunization. J Exp Med; 209(6): 1091-103.

78. Strokappe N, Szynol A, Aasa-Chapman M, Gorlani A, Forsman Quigley A, et al. (2012) Llama antibody fragments recognizing various epitopes of the CD4bs neutralize a broad range of HIV-1 subtypes A, B and C. PLoS One; 7(3): e33298.

79. Harbury PB, Zhang T, Kim PS, Alber T (1993) A switch between two-, three-, and four-stranded coiled coils in GCN4 leucine zipper mutants. Science; 262(5138): 1401-7.

80. de Haard HJ, Kazemier B, Koolen MJ, Nijholt LJ, Meloen RH, et al. (1998) Selection of recombinant, library-derived antibody fragments against p24 for human immunodeficiency virus type 1 diagnostics. Clin Diagn Lab Immunol; 5(5): 636-44.

81. Pancera M,Wyatt R (2005) Selective recognition of oligomeric HIV-1 primary isolate envelope glycoproteins by potently neutralizing ligands requires efficient precursor cleavage. Virology; 332(1): 145-56.

82. Derdeyn CA, Decker JM, Sfakianos JN, Wu X, O'Brien WA, et al. (2000) Sensitivity of human immunodeficiency virus type 1 to the fusion inhibitor T20 is modulated by coreceptor specificity defined by the V3 loop of gp 120 . J Virol; 74(18): 8358-67.

83. Wei X, Decker JM, Liu H, Zhang Z, Arani RB, et al. (2002) Emergence of resistant human immunodeficiency virus type 1 in patients receiving fusion inhibitor (T-20) monotherapy. Antimicrob Agents Chemother; 46(6): 1896905.

84. Li M, Gao F, Mascola JR, Stamatatos L, Polonis VR, et al. (2005) Human immunodeficiency virus type 1 env clones from acute and early subtype B infections for standardized assessments of vaccine-elicited neutralizing antibodies. J Virol; 79: 10108-25.

85. Langedijk JP, Brandenburg AH, Middel WG, Osterhaus A, Meloen RH, et al. (1997) A subtype-specific peptide-based enzyme immunoassay for detection of antibodies to the $\mathrm{G}$ protein of human respiratory syncytial virus is more sensitive than routine serological tests. J Clin Microbiol; 35(7): 1656-60.

86. Slootstra JW, Puijk WC, Ligtvoet GJ, Langeveld JP, Meloen RH (1996) Structural aspects of antibody-antigen interaction revealed through small random peptide libraries. Mol Divers; 1(2): 87-96.

87. Battye TG, Kontogiannis L, Johnson O, Powell HR, Leslie AG (2011) iMOSFLM: a new graphical interface for diffraction-image processing with MOSFLM. Acta Crystallogr D Biol Crystallogr; 67(Pt 4): 271-81.

88. Evans P (2006) Scaling and assessment of data quality. Acta Crystallogr D Biol Crystallogr; 62(Pt 1): 72-82.

89. McGoy AJ, Grosse-Kunstleve RW, Adams PD, Winn MD, Storoni LC, et al. (2007) Phaser crystallographic software. J Appl Crystallogr; 40(Pt 4): 658-674. 
90. Perrakis A, Morris R, Lamzin VS (1999) Automated protein model building combined with iterative structure refinement. Nat Struct Biol; 6: 458-463.

91. Emsley P,Cowtan K (2004) Coot: model-building tools for molecular graphics. Acta Crystallogr D Biol Crystallogr; 60: 2126-2132.

92. Murshudov GN, Vagin AA, Dodson EJ (1997) Refinement of macromolecular structures by the maximum-likelihood method. Acta Crystallogr D Biol Crystallogr; 53: 240-255.

93. Favier A,Brutscher B (2010) Recovering lost magnetization: polarization enhancement in biomolecular NMR. J Biomol NMR; 49(1): 9-15.

94. Delaglio F, Grzesiek S, Vuister GW, Zhu G, et al. (1995) NMRPipe: a multidimensional spectral processing system based on UNIX pipes. J Biomol NMR; 6(3): 277-93.

95. Vranken WF, Boucher W, Stevens TJ, Fogh RH, Pajon A, et al. (2005) The CCPN data model for NMR spectroscopy: development of a software pipeline. Proteins; 59(4): 687-96.

96. Markley JL, Bax A, Arata Y, Hilbers CW, Kaptein R, et al. (1998) Recommendations for the presentation of NMR structures of proteins and nucleic acids. IUPAC-IUBMB-IUPAB Inter-Union Task Group on the Standardization of Data Bases of Protein and Nucleic Acid Structures Determined by NMR Spectroscopy. J Biomol NMR; 12(1): 1-23.

97. de Vries SJ, van Dijk M, Bonvin AM (2010) The HADDOCK web server for data-driven biomolecular docking. Nat Protoc; 5(5): 883-97.

98. Brunger AT, Adams PD, Clore GM, DeLano WL, Gros P, et al. (1998) Crystallography \& NMR system: A new software suite for macromolecular structure determination. Acta Crystallogr D Biol Crystallogr; 54(Pt 5): 905-21.

99. Krzeminski M, Loth K, Boelens R, Bonvin AM (2010) SAMPLEX: automatic mapping of perturbed and unperturbed regions of proteins and complexes. BMC Bioinformatics; 11: 51 .

100. Shen Y, Delaglio F, Cornilescu G, Bax A (2009) TALOS+: a hybrid method for predicting protein backbone torsion angles from NMR chemical shifts. J Biomol NMR; 44(4): 213-23.

101. Fernandez-Recio J, Totrov M, Abagyan R (2004) Identification of proteinprotein interaction sites from docking energy landscapes. J Mol Biol; 335(3): 843-65.

102. Brugger B, Glass B, Haberkant P, Leibrecht I, Wieland FT, et al. (2006) The HIV lipidome: a raft with an unusual composition. Proc Natl Acad Sci U S A; 103(8): 2641-6.

103. Langedijk JP, Zekveld MJ, Ruiter M, Corti D, Back JW (2011) Helical peptide arrays for lead identification and interaction site mapping. Anal Biochem; 417(1): 149-55.

104. de Rosny E, Vassell R, Jiang S, Kunert R, Weiss CD (2004) Binding of the 2F5 monoclonal antibody to native and fusion-intermediate forms of human immunodeficiency virus type 1 gp41: implications for fusion-inducing conformational changes. J Virol; 78(5): 2627-31.

105. Dimitrov AS, Jacobs A, Finnegan CM, Stiegler G, Katinger H, Blumenthal R (2007) Exposure of the membrane-proximal external region of HIV-1 gp41 in the course of HIV-1 envelope glycoprotein-mediated fusion. Biochemistry; 46(5): 1398-401.

106. Crooks ET, Tong T, Osawa K, Binley JM (2011) Enzyme digests eliminate nonfunctional Env from HIV-1 particle surfaces, leaving native Env trimers intact and viral infectivity unaffected. J Virol; 85(12): 5825-39.

107. Karlsson Hedestam GB, Fouchier RA, Phogat S, Burton DR, Sodroski J, et al. (2008) The challenges of eliciting neutralizing antibodies to HIV-1 and to influenza virus. Nat Rev Microbiol; 6(2): 143-55.

108. Frey G, Chen J, Rits-Volloch S, Freeman MM, Zolla-Pazner S, et al. (2010) Distinct conformational states of HIV-1 gp41 are recognized by neutralizing and non-neutralizing antibodies. Nat Struct Mol Biol; 17(12): 1486-91.

109. Mouquet H, Warncke M, Scheid JF, Seaman MS, Nussenzweig MC (2012) Enhanced HIV-1 neutralization by antibody heteroligation. Proc Natl Acad Sci U S A; 109(3): 875-80.

110. Alam SM, McAdams M, Boren D, Rak M, Scearce RM, Gao F, Camacho ZT, et al. (2007) The role of antibody polyspecificity and lipid reactivity in binding of broadly neutralizing anti-HIV-1 envelope human monoclonal antibodies $2 \mathrm{~F} 5$ and $4 \mathrm{E} 10$ to glycoprotein 41 membrane proximal envelope epitopes. J Immunol; 178(7): 4424-35.

111. Sanchez-Martinez S, Lorizate M, Katinger H, Kunert R, Nieva JL (2006) Membrane association and epitope recognition by HIV-1 neutralizing antigp41 2F5 and 4E10 antibodies. AIDS Res Hum Retroviruses; 22(10): 9981006.

112. Song L, Sun ZY, Coleman KE, Zwick MB, Gach JS, et al. (2009) Broadly neutralizing anti-HIV-1 antibodies disrupt a hinge-related function of gp41 at the membrane interface. Proc Natl Acad Sci U S A; 106(22): 9057-62.

113. Zhou T, Georgiev I, Wu X, Yang ZY, Dai K, et al. (2010) Structural Basis for Broad and Potent Neutralization of HIV-1 by Antibody VRC01. Science; 329(5993): 811-7.

114. Nicely NI, Dennison SM, Spicer L, Scearce RM, Kelsoe G, et al. (2010) Crystal structure of a non-neutralizing antibody to the HIV-1 gp41 membraneproximal external region. Nat Struct Mol Biol; 17(12): 1492-4.

115. Timmerman P, Beld J, Puijk WC, Meloen RH (2005) Rapid and quantitative cyclization of multiple peptide loops onto synthetic scaffolds for structural mimicry of protein surfaces. Chembiochem; 6(5): 821-4.

116. Mascola JR, D'Souza P, Gilbert P, Hahn BH, Haigwood NL, et al. (2005) Recommendations for the design and use of standard virus panels to assess neutralizing antibody responses elicited by candidate human immunodeficiency virus type 1 vaccines. J Virol; 79(16): 10103-7. 